\title{
Relief and ecological niche of mute swan (Cygnus olor (Gmelin, 1803)) wintering in Sivash
}

\author{
A.V. Zhukov', A.Yu. Andryushchenko² \\ ${ }^{1}$ Oles Honchar Dnipropetrovsk National University, Dnipro, Ukraine \\ ${ }^{2}$ Bogdan Chmelnitskiy Melitopol State Pedagogical University, Melitopol, Ukraine \\ E-mail: isweetcherry92@gmail.com
}

We evaluated the role of terrain as a factor determining the spatial distribution of Mute Swan wintering in the conditions of the Gulf of Siwash. It was found that the number of clusters of mute swans wintering in Sivash subordinate to the lognormal distribution. The arithmetic mean value of the number of clusters is $532.1 \pm 203.1$ induviduals, median is 129 ind. with a range from 5 to 8.000 ind. Deviation from the normal law of the number of animals can be seen as the result of the impact of limiting factors. The article confirm the hypothesis that the relief is a synthetic reflection of the ecological environment, which determines the spatial distribution of wintering mute swans. We proved that for the quantitative characterization of the relief the digital elevation model and derived data layers that reveal different aspects of the functional significance of the earth's surface as a factor in organizing the structure of the living cover are very important. Axis with 1-4 marginality and specialization, resulting from ENFA-procedure, was significantly different from random alternatives. This indicates that ecogeographic variables selected as prospective predictors are able to identify some of the features of the ecological niche of wintering mute swan. The greatest marginality was characterized by categorical variables that indicate various forms of relief. The greatest preference was registered for various open slopes while the continual variables complement the features of these habitats. Open slopes, naturally, are characterized by a large factor in the erosion, they have more rugged terrain and geomorphological conditions of areas with great diversity. Continual variables are also characterized by a large value in determining the ecological niche specialization of mute swan. Multiple scale organization of the geographical landscape causes the hierarchical organization of the ecological niche. Properties of ecological niches at different scale levels indicate that the nature of perception of reality geomorphological mute swan is significantly different depending on the transmission window size, which determines the level of a large-scale review of the ecological niche. There is certain variation in distance where geomorphological predictors are not able to statistically reflect the particular spatial bird distribution. Properties with marginality tend to appear even at one kilometer distances, whereas properties with specialization - a distance of more than $6 \mathrm{~km}$. At different ranges, some predictors of transmission windows can be inverted: the variability determines the ecological niche with inverted value. Direct gradient analysis allowed us to evaluate the projection of the ecological niche on the individual axes of ecological spatial pattern. Analysis within the HOF-concept showed that the variation of wintering mute swans abundance along the gradient of geomorphological variables could noe be described by the type I model, i.e the mute swan number depends on the geomorphological conditionsof habitat. Another important result is that the gradients for many predictors are unbalanced and/or bimodal.

Key words: ecological niche; wintering mute swans; relief; digital elevation model; factor analysis; marginalization; specialization 


\title{
Роль рельефа в организации экологической ниши лебедя- шипуна (Cygnus olor(Gmelin, 1803)) на зимовке в Присивашье
}

\author{
А.В. Жуков ${ }^{1}$, А.Ю. Андрющенко ${ }^{2}$ \\ 'Днепропетровский национальный университет имени Олеся Гончара, Днепр, Украина \\ ${ }^{2}$ Мелитопольский государственный педагогический университет имени Богдана Хмельницкого, \\ Мелитополь, украина, E-mail: isweetcherry92@gmail.com
}

В работе оценена роль рельефа как фактора, определяющего пространственное размещение лебедя-шипуна на зимовке в условиях залива Сиваш. Установлено, что численность скоплений лебедя-шипуна на зимовке в Присивашье подчиняется лог-нормальному распределению. Среднее арифметическое значение численности

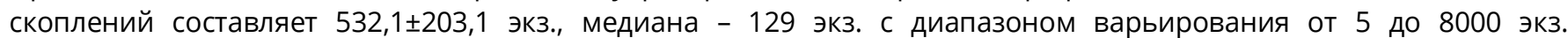
Отклонение от нормального закона численности животных может рассматриваться как результат воздействия лимитирующих факторов. В работе полученны подтверждения гипотезы о том, что рельеф является синтетическим отражением экологической обстановки, которая определяет пространственное размещение лебедя-шипуна на зимовке. Показано, что для количественной характеристики рельефа большое значение имеет цифровая модель рельефа и производные информационные слои, которые раскрывают различные аспекты функционального значения поверхности земли как фактора, организующего структуру живого покрова. Оси маргинальности и специализации 1-4, полученные в результате ENFA-процедуры, статистически достоверно отличаются от случайной альтернативы. Это свидетельствует о том, что выбранные в качестве предполагаемых предикторов экогеографические переменные, в действительности способны определять некоторые особенности экологической ниши лебедя-шипуна на зимовке. Наибольшей маргинальностью характеризуются категориальные переменные, которые указывают на различные формы рельефа. Наибольшим предпочтением отличаются открытые склоны. Континуальные переменные дополняют особенности этих стаций. Открытые склоны, закономерно, характеризуются большим фактором эрозии, находятся в более пересеченной местности и в условиях большего геоморфологического разнообразия местности. Континуальные переменные характеризуются большим значением в определении специализации экологической ниши лебедя-шипуна. Полимасштабная организация географического ландшафта является причиной иерархической организации экологической ниши. На различных масштабных уровнях свойства экологической ниши проявляют себя поразному. Свойства экологической ниши на разных масштабных уровнях указывают на то, что характер восприятия геоморфологической реальности лебедем-шипуном существенно различен в зависимости от размеров окна пропускания, определяющего масштабный уровень рассмотрения экологической ниши. Существует определенный диапазон дистанций, в пределах которых геоморфологические предикторы не способны статистически достоверно отразить особенности расположения животных в пространстве. Свойства маргинальности начинают проявляться уже при дистанциях около километра, а специализации - с дистанций более 6 км. На разных диапазонах окна пропускания некоторые предикторы могут проявлять инверсию: изменчивость с точностью до наоборот отражает свое значение для определения экологической ниши. Прямой градиентный анализ позволил оценить проекции экологической ниши на отдельные оси экологического пространства. Анализ в рамках HOF-концепции показал, что варьирование численности лебедя-шипуна на зимовке в градиенте геоморфологических переменных не описывается моделью типа I, т.е. численность находится в зависимости от геоморфологической обстановки. Также важным результатом является то, что градиенты для многих предикторов являются несимметричными и (или) бимодальными.

Ключевые слова: экологическая ниша, зимовка, рельеф, цифровая модель рельефа, факторный анализ экологической ниши, маргинальность, специализация

Гусеобразные живут во всех ландшафтно-географических зонах. Биология большинства видов связана с пресными, засоленными и солоноватыми водоемами (Lysenko, 1991). В природе требования питания гусепообразных удовлетворяет довольно ограниченное число мест обитания, прежде всего это монотипичные заросли однодольных (в них при сощиповании не страдает меристема), которые находятся на начальных стадиях роста. Зимой для этой цели идеально подходят злаковые луга немного южнее снеговой линии. В более южных районах они быстро растут и грубеют, а севернее - находятся под снегом или не растут. Альтернативный вариант 
- сочные подводные части полуводных злаков, камышей, осок в мелководных водно-болотных угодьях на юг от зоны замерзания водоемов (Kondratyev, 2002).

Рельеф представляет собой совокупность различных по своей морфологии, генезису и возрасту форм и элементов земной поверхности, а также является отражением их пространственных отношений (Boltramovich et al., 2005). Анализ рельефа является средством познания ландшафта, основываясь на цифровой модели рельефа (ЦМР или в английской транскрипции DEM - Digital Elevation Model). Пространственное распределение топографических атрибутов может быть использовано для непрямого измерения пространственнной изменчивости гидрологических, геоморфологических и биологических процессов (Moore et al., 1993). Baжными параметрами рельефа являются формы рельефа (landforms), или единицы рельефа, каждая из которых несет информацию о физических, химических и биологических процессах и параметрах (Dehn et al., 2001).

Сиваш (Гнилое море, Сиваши) - мелководный залив лагунного типа в западной части Азовского моря находится в южной части Украины в области перехода ее основной континентальной части в полуостровную Крым. Протяженность Сиваша с юга на север составляет 115 км, с запада на восток - 160 км, его общая площадь с островами и отмелями составляет около 2600 км кв. Залив характеризуется очень сложной конфигурацией береговой линии, неустойчивостью водной поверхности, которая вызывается сгонно-нагонными процессами, и значительными отличиями физико-биохимических показателей в разных частях (Matsyura, 2011).

Сивашский природный комплекс занимает территории Северного, Южного, Центрального и Западного и Восточного Сиваша. Площади с условно нетрансформированными геокомплексами составляют 5,06 \%, слабо трансформированными - 14,29 \%, существенно трансформированными - 28,91 \%, а полностью деградированными - 14,8\% территории (Siokhin et al., 2014).

К водно-аккумулятивным геоморфологическим элементам морского происхождения относятся песчаноракушковые косы, пересыпи и Сивашская низменность. Песчано-ракушковые косы, пересыпи и острова распространены вдоль северного побережья. Генезис кос тесно связан с геологическим строением коренного берега, мелководностью моря и физико-геологическими процессами, которые проявляются на побережьях (Landshafty.., 1985; Priroda.., 1987). Образованы они преимущественно песчаными и песчано-ракушковыми отложениями. Более 10 тыс. га приходится на острова, которые служат не только местом гнездования большого количества околоводных птиц, но и скопления перелетных видов (Sabinevskiy, 1977; Inventarizatsiya.., 1993; Kolomiychuk, Matsyura, 1998; Matsyura, 1999, 2011).

Ландшафтную структуру Сиваша и Присивашья определяют такие основные типы (Marushevskiy et al., 2005):

1. Равнинно-волнообразная приморская террасовая местность. Этот тип местности с каштановыми и сильносолонцеватыми почвами в комплексе с солонцами (до 20-50\%) на лессовидных суглинках занимает около 65\% площади Присивашья. Это различные по высоте возвышения, находящиеся между подами-долинами. В растительном покрове преобладают полынно-злаковые ценозы.

2. Приморские долинно-подовые солончаковые территории занимают около 23\% площади региона. Этот тип местности представлен относительно глубокими подами-долинами, большинство которых сформированы в замкнутые котловины и не соединяются с Сивашом. Встречаются также долины, впадающие в Сиваш. Основной тип растительности - солончаковые луга, используемые в качестве сенокосов и пастбищ. Подыды-долины- это достаточно глубокие (до 10-15 м) замкнутые плоскодонные кот-ловины разнообразных конфигураций с крутыми и высокими склонами. Поды-долины характеризуются высоким уровнем сильно засоленных почвенных вод (2-5 м). Сельскохозяйственное использование земель подово-долинных территорий ограничено значительной засоленностью почв и близким расположением минерализованных почвенных вод.

3. Приморские солончаковые местности занимают около 12\% площади региона. Эти территории формируются в условиях постоянного подтопления и периодического затоп-ления морскими водами открытых подов-долин и низких аккумулятивных участков Сиваша. По характеру растительности выделяют солончаковые урочища с лугово-со-лончаковой растительностью, солончаковые урочища с суккулентными галофитами, илистые солончаки без растительности.

4. Поднятые островные участки и участки постоянного нагонного подтопления.

5. Местность засолено-луговых участков, граничащих с участками нагонного (периодического и кратковременного) подтопления. Преобладает луговая растительность.

6. Песчано-ракушечниковые косы, пересыпи, острова на осадочных породах.

7. Ландшафт лагунного типа. Сюда входит Сиваш.

8. Ландшафт Арабатской стрелки.Это песчано-ракушечниковая коса с характерной солончаковой растительностью и солянково-полынно-степными урочищами (Marushevskiy et al., 2005).

Для ландшафтов Присивашья характерна гидроморфная поясность, связанная с изменением уровня за соленных грунтовых вод в пространстве (от 0 до 6-8 м) и во времени (в зависимости от уровня Сиваша). Ландшафтная структура Сиваша имеет следующие особенности (Leontyev, Leontyev, 1956; Pozachenyuk, 1986; Mikhaylov, 2006).

1. Пояс недренированных равнин(УГВ 0.2-0.5 м) - низкие равнины, сложенные лагунными илами, включает следующие зоны: 
- зона«вторичных» лагун - мелководные озера и заливы, полностью или частично отчлененные от основной акватории Сиваша песчано-ракушечными пересыпями или цепочкой аккумулятивных островков; летом в них наблюдается«садка» соли;

- зона«засух» - субгоризонтальные поверхности, попеременно то обсыхающие(при сгонах и длительной жаркой погоде), то затопляемые(при нагонах и во время дождей);

- зона корковых солончаков («такыры») - плоские участки, сложенные высохшими илами, разбитыми трещинами на полигональные отдельности, с редкой солончаковой растительностью;

- зона солянковых зарослей.

2. Пояс слабодренированных равнин («палеолагунная» зона, УГВ от 0.2-0.5 до 2.5-3.0 м), преобладают полынно-типчаковые полупустынные степи в комплексе с галофитными лугами.

3. Пояс относительно дренированных лессовых равнин(УГВ 3-8 и ниже), господствуют обедненные варианты ковыльно-типчаковых настоящих степей и сухие луга, практически полностью сведенные.

Маркером уровня грунтовых вод может быть такой производный от ЦМР показатель, как высота над русловой сетью (Bock, Köthe, 2008).

Растительный покров береговой зоны играет важную роль в развитии ветроосушных берегов залива Сиваш. Выделяются следующие типы растительности: солонецовая, солончаковая (коротко-, средне- и длительнозаливная), водная растительность (прибережных участков и мелководья), полыново-злаковая степная (участкипобережья, где высота клифов превышает 4 м, что ограничивает заливание прибрежных участков ропой) (Davydov et al., 2013). А.В. Мацюра (2011) считает целесообразным выделение двух типов островных систем: острова материкового происхождения и острова и косы аккумулятивного происхождения, поскольку гидрология островов является одним из основных факторов распределения растительности.

Показано, что максимальное видовое разнообразие гнездящихся птиц характерно для наиболее мозаичных биотопов с хорошими кормовыми и защитными условиями (Matsyura, 2011).

Местообитание характеризуется наличием на некоторой территории ресурсов и условий для данного вида, в результате чего становится возможной заселенность этой территории, включая его выживание и размножение (Hall et al., 1997). Целью изучения выбора местообитаний видами состоит в выявлении характеристик окружающей среды, которые делают место пригодным для существования вида (Calenge, 2006).

Экологическая ниша является полезной моделью для описания выбора местообитаний видом. Хатчинсон (Hutchinson, 1957) определяет экологическую нишу как гиперобъем в многомерном пространстве, определяемом переменными окружающей среды, где вид потенциально может поддерживать жизнеспособность популяций. Методически экологическая ниша может быть исследована средствами общего факторного анализа системы экологическая ниша-среда (general Niche-environment system factor analysis - GNESFA) (Calenge, Basille, 2008).

В основе факторного анализа экологических ниш лежит предположение о том, что виды распределены неслучайно относительно экогеографических переменных (Hirzel et al., 2002). Интересующий вид может характеризоваться некоторой маргинальностью (что выражается в отличии видового среднего от глобального среднего значения экогеографической переменной) и некоторой специализацией (что проявляет себя в том, что видовая дисперсия меньше глобальной дисперсии).

GNESFA может быть реализован в виде трех версий - FANTER, ENFA и MADIFA. Факторный анализ экологической ниши со средой в качестве референтного распределения (Factor analysis of the niche, taking the environment as the reference - FANTER) рассматривает деформацию экологической ниши относительно экологического пространства, которое принято как референтное, т.е. оси этого пространства приводят к такому состоянию, что экологическое пространство имеет идеальную сферическую форму. Напротив, сферическая форма придается экологической нише в анализе MADIFA (Mahalanobis distances factor analysis), а искривление экологического пространства указывает на степень отличия свойств среды от экологического оптимума вида. По результатам MADIFA может быть построена наиболее корректная карта предпочтения местообитаний данным видом (Calenge et al., 2008).

Возможна особая точка зрения, при которой два распределения вместе (экологическая ниша и экологическое пространство) рассматриваются как фокусное и референтное. Эта симметричная точка зрения имеет преимущество вне выбора референтного распределения. Этот особый случай является основой факторного анализа экологической ниши (Ecological-niche factor analysis - ENFA). B ENFA первая ось полностью соответствует маргинальности, а последующие оси описывают специализацию вида. Интеграция этих осей также дает возможность построить карту предпочтения местообитаний, но в отличии от MADIFA, этот результат в рамках ENFA не является математически состоятельным.

H. Карузо и соавт. (Caruso et al., 2015) отмечают, что несмотря на преимущества GNESFA, этот вид анализа мало представлен в научной литературе. Даже после публикации работы (Calenge, Basille, 2008) в ряде статей продолжают пользоваться ENFA подходом не только для как исследовательским средством, но и для построения карт предпочтения местообитания (De Angelo et al., 2011; Galparsoro et al., 2009; Valle et al., 2011). Ряд авторов применяют только MADIFA для описания распределения видов (Halstead et al., 2010; Hemery et al., 2011; Thiebot et al., 2011). Наряду с оригинальной работой (Calenge, Basille, 2008) в статье Н. Карузо и соавт. (Caruso et al., 2015) для описания экологической ниши пумы в южной Америке с применением всех техник GNESFA. 
Градиентный анализ был разработан Раменским и назван Уиттекером прямым градиентным анализом (Whitteker, 1967). Этот подход позволяет моделировать ответ видов на градиенты окружающей среды. Существует несколько алгоритмов для описания отношения видов к условиям окружающей среды. Часто очень сложно решить, какой уровень сложности необходим для получения адекватного отображения связи. Был предложен перечень иерархических моделей, которые сочетают стремление получить простые и ясно интерпретируемые результаты с необходимостью учесть различные варианты формы экологических ниш (Huisman et al., 1993). Ответ вида вдоль градиенты окружающей среды можно рассматривать как одно из сечений экологической гиперниши. Даже если принять, что физиологическая ниша вида имеет простую (унимодальную) форму, то нет оснований предполагать, что реализованная ниша должна быть также простой. Хусман, Олф и Фреско предложили пять иерархических моделей (Huisman-Olff-Fresco - HOF-модели). В рамках пакета eHOF (https://cran.rproject.org/web/packages/eHOF/) предложено ещё две дополнительных модели (Jansen, Oksanen, 2013).

Целью нашей работы является оценить роль рельефа как фактора, определяющего пространственное размещение лебедя-шипуна на зимовке в условиях залива Сиваш.

\section{Методы}

Исследования проведены в водно-болотных угодьях залива Сиваш в зимние сезоны 2012-2016 гг. В процессе исследования учитывались все гусеобразные, независимо от биотопа и места их нахождения. Применялись две основных методики автомобильных учетов: по трансекте и точечный (Andryushchenko, 2009; Andryushchenko et al., 2010). Учет по трансекте проводился в зональных ландшафтах и велся на челночных автомобильных маршрутах в пределах квадратов, размером 10×10 км, а в водно-болотных угодьях - вдоль береговой линии. Ширина учетного коридора при хорошей видимости составляла 7-8 км, во время дождя и снегопада - 2-4 км, в тумане - до 500 м (в указанных границах она была максимальной для больших видов, а минимальной - для мелких птиц и особей, которые находились в сомкнутых биотопах с ограниченным обзором). Обследование исследуемой территории осуществлялось на внедорожном автомобиле, что позволяло проезжать по оттаявшей почве и умеренно глубокому снегу, в том числе преодолевать большие лужи и замёты. Точечный учет проводился во время остановок при обзоре однообразных открытых территорий и разных водоемов. Во всех случаях территории и акватории осматривалась в 12-Х бинокли и 60-Х телескопы. В зависимости от продолжительности дня и качества освещенности учеты проводились на протяжении всего светлого времени суток с 7:00-7:30 по 15:30-16:00. Кроме видовой принадлежности фиксировались численность, биотоп, географические координаты одиночных птиц и центров больших скоплений, а также, если была возможность, возраст и пол птиц (Андрющенко, 2009). Данные учетов записывались в специальные карточки, наносились на карты масштабом 1:200000, а потом переносились в географическую информационную базу данных, созданную в программном продукте ArсMар 10.0. Статистические вычисления произведены с помощью программной оболочки Project R «R: A Language and Environment for Statistical Computing».

Топографический индекс влажности. Концепция топографического индекса влажности (topographic wetness index - TWI) впервые была предложена К. Бивеном и Н. Киркби (1979). Топографический индекс влажности вычисляется по формуле:

$$
\mathrm{TWI}=\ln (a / \tan \beta),
$$

где $a$ - дренажная площадь (площадь водосбора, рассчитанная на единицу длины замыкающего контура), $\beta$ крутизна склона (Moore et al., 1993; Kunakh, Papka, 2015).

Индекс топографического положения. Индекс топографического положения (Topographic position index - TPI) представляет собой разность между абсолютной высотой данной точки (или ячейки) и средней высотой точек в определенном буфере вокруг исходной точки. Положительные значения ТPI соответствуют выпуклостям земной поверхности; отрицательные - понижениям; значения, близкие к нулю, могут указывать как на равнинную поверхность, так и среднюю часть склона (Guisan et al., 1999; Kunakh, Papka, 2015).

Индекс баланса геомассы. Индекс баланса геомассы (Mass Balance Index) раскрывает топографические предпосылки к разрушению и отложению грунтов. Данный показатель позволяет выявить участки с высокой степенью вероятности развития осыпных склоновых процессов (Moeller et al., 2008). Негативные значения индекса указывают на участки с накоплением геомассы, такие как депрессии рельефа или поймы рек. Позитивные значения указывают на участки с высокой степенью риска эрозионных процессов. Значение индекса, близкое к нулю, указывает на участки с равновесием убыли и прибыли геомассы (Kunakh, Papka, 2015).

Фактор эрозии LS. Эрозионный потенциал рельефа LS является одним из компонентов универсального уравнения почвенной эрозии (Universal Soil Loss Equation - USLE). LS является произведением L- и S-факторов. Lфактор определяет значение длины склона (slope length), a S-фактор - крутизны (slope steepness). Универсальное уравнение эрозионных потерь почвы (USLE), или уравнение Уишмейера-Смита, выведено в США в качестве метода расчета среднегодовых потерь почвы на основе обобщения результатов наблюдений на стандартных стоковых площадках длиной 22,13 м и с уклоном 9 \%, проведенных более чем на 8000 участках в 21 штате (Mitchel, Bubenzer, 1984; Lisetskiy, Polovinko, 2012). В первой редакции USLE для описания влияния крутизны склона использовали тангенс, а для показателя степени при длине склона - постоянную величину, равную 0,5. Позже тангенс угла наклона поверхности заменили на синус, т.к. было установлено, что с помощью этой функции 
удается более точно отразить влияние уклона на склонах крутизной более $3^{\circ}$ (Wischmeier, Smith, 1978). Эрозионные потери почвы гораздо более чувствительны к изменению крутизны склонов, чем к изменению длины, поэтому усовершенствованная модель USLE - RUSLE была направлена на наиболее точную оценку фактора крутизны склонов (McCool et al., 1994; Lisetskiy, Polovinko, 2012; Kunakh, Papka, 2015).

Прямая и рассеянная инсоляции. Прямая и рассеянные инсоляции относятся к категории топоклиматических показателей (Boehner, Antonic, 2009). Наиболее отличительные вариации климатических паттернов возникают по причине топоклиматических процессов, происходящих в пограничном слое Земли и имеющих характеристическую размерность не более чем $10^{1} \mathrm{~km}$ (мезо $\beta$ масштаб) и до 10-3 км (микро $\beta$ масштаб) (масштабные уровни приведены по Orlanski, 1975). Топоклиматология является частью климатологии, которая занимается изучением воздействия земной поверхности на климат. Земная поверхность преимущественно контролирует пространственную дифференциацию приземных атмосферных процессов и связанных с этим климатических вариаций (Boehner, Antonic, 2009). Солнечная радиация, попадающая на земную поверхность, состоит из двух составляющих - коротковолновой и длинноволновой. Для вычисления коротковолновой составляющей необходимо учитывать оценку прямой и диффузной компонент, которые попадают на открытую поверхность с оценкой всех эффектов, которые вызваны топографией поверхности и специфичных для каждой компоненты (Boehner, Antonic, 2009; Kunakh, Papka, 2015).

Высота над русловой сетью. Высота над русловой сетью (Altitude above channel network), или вертикальная дистанция до русловой сети (Vertical Distance to Channel Network - VDTCN), является разницей между высотой рельефа и высотой русловой сети (Olaya, Conrad, 2008) (рис. 1). Является надежным маркером уровня грунтовых вод и может быть использован для картографии почв (Bock, Köthe, 2008; Kunakh, Papka, 2015).

Векторная мера пересеченности местности. Векторная мера пересеченности местности (Vector Ruggedness Measure - VRM) оценивает дисперсию ортогональных к поверхности рельефа векторов. Значение VRM низкое как для плоской местности, так и для крутой местности, но высокое для крутой и пересеченной (Sappington et al., 2007). Пересеченность понимается как негладкость поверхности (Kunakh, Papka, 2015).

Семь HOF-моделей прямого градиентного анализа представляют собой усложняющийся ряд (Jansen, Oksanen, 2013. Вероятно, наиболее важной моделью является модель I, которая представляет собой плоский ответ, который значит отсутствие значительного тренда вдоль градиента для данного вида. Эта модель является нульгипотезой, которая указывает на то, что только вид с четким ответом на фактор среды может описываться одной из прочих шести моделей. Форма модели II является монотонной сигмоидой с максимумом на одной из границ градиента. Модель III является монотонной сигмоидой с плато вблизи максимального значения обилия вида. Модель IV представляет каноническую форму ответа вида - унимодальная и симметричная. Модель V является унимодальной ассиметричной. Модели VI и VII имеют два оптимума, модель VI - с равными максимумами (Jansen, Oksanen, 2013).

\section{Результаты и обсуждение}

Анализ полученных результатов свидетельствует о том, что данные по численности скоплений лебедя-шипуна подчиняются лог-нормальному распределению (рис. 1). Среднее арифметическое значение численности скоплений составляет 532,1 203,1 экз., медиана - 129 экз. с диапазоном варьирования от 5 до 8000 экз. Среднее арифметическое случайной величины, распределение которой существенно отличается от нормального закона, является смещенной оценкой среднего генеральной совокупности. Среднее геометрическое является состоятельной оценкой среднего в случае, когда случайная величина подчиняется лог-нормальному закону. В нашем случе геометрическое среднее составляет 147,6 экз., а в 95 \% случаях численность скоплений находится в диапазоне от 91,7 до 237,4 эк3. Коэффициент вариации натуральных данных по численности скоплений составляет $250,3 \%$.

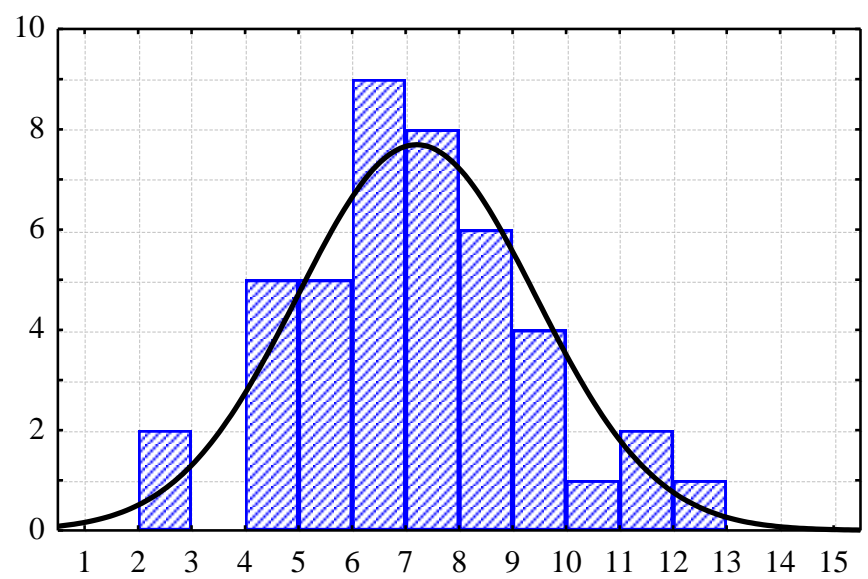

Рис. 1. Гистограмма распределения численности скоплений лебедя-шипуна (данные логарифмированы по основанию 2) 
На рис. 2 представлена информация о пространсвтенном размещении скоплений лебедя-шипуна на зимовке в заливе Сиваш. Следует отметить, что результирующая картина зависит как от реального распределения животных (объективная компонента), так и от характера организации маршрута обследования территории (субъективно-методическая компонента). Экспресс-оценка полученных результатов свидетельствует о тяготении мест скоплений лебедя-шипуна к прибрежным участкам, что вполне закономерно и тривиально для водоплавающего вида птиц. Однако открытым остается вопрос о факторах, которые определяют пространственное размещение скоплений и их численность. Можно предположить, что природа таких факторов может быть весьма разнообразна. В нашем исследовании мы остановимся на выяснении вопроса о характере влияния рельефа на пространственное размещение скоплений лебедя-шипуна на зимовке.

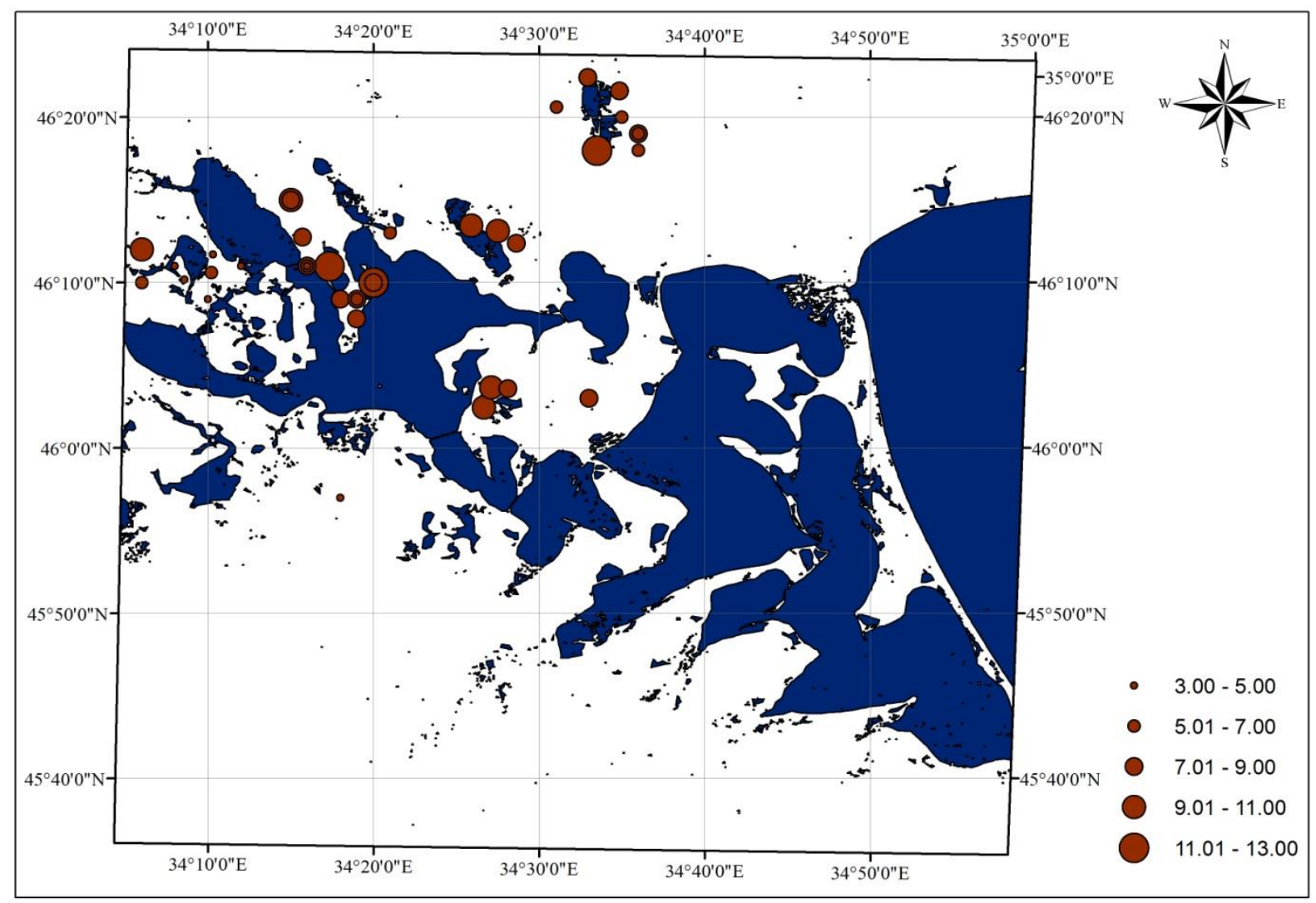

Рис. 2. Размещение точек встреч лебедя-шипуна (численность представлена в логарифмическом масштабе)

Для количественной характеристики рельефа нами использована цифровая модель рельефа и производные информационные слои, которые раскрывают различные аспекты функционального значения поверхности земли как фактора, организующего структуру живого покрова. Для изученной территории характерен равнинный рельеф с перепадом высот 0-41,0 м (табл. 1).

Таблица 1. Описательные статистики экогеографических переменных

\begin{tabular}{lcccccccc}
\hline \multicolumn{1}{c}{ Variable } & Mean \pm St. Error & St. Deviation & Медиана & Min & Max & Range & Asymmetry & Excess \\
dem & $13,73 \pm 0,03$ & 8,29 & 12,31 & 0,00 & 41,00 & 41,00 & 0,50 & $-0,54$ \\
twi & $10,09 \pm 0,01$ & 3,91 & 10,68 & 5,00 & 21,54 & 16,54 & $-0,03$ & $-1,08$ \\
tpi & $0,00 \pm 0,00$ & 1,00 & $-0,02$ & $-4,06$ & 6,51 & 10,56 & 0,08 & 1,13 \\
mbi & $0,21 \pm 0,002$ & 0,56 & 0,00 & $-0,75$ & 2,66 & 3,41 & 1,45 & 1,64 \\
Is & $0,10 \pm 0,000$ & 0,03 & 0,10 & 0,06 & 0,48 & 0,42 & 1,59 & 3,63 \\
dir & $6,46 \pm 0,000$ & 0,01 & 6,46 & 6,30 & 6,55 & 0,25 & $-0,14$ & 4,65 \\
diff & $1,35 \pm 0,000$ & 0,01 & 1,35 & 1,34 & 1,35 & 0,01 & $-0,49$ & $-0,55$ \\
vert & $4,72 \pm 0,02$ & 4,40 & 3,75 & 0,00 & 25,80 & 25,80 & 0,80 & $-0,13$ \\
vrm & $3,76 \pm 0,01$ & 1,97 & 3,00 & 0,00 & 22,73 & 22,73 & 1,69 & 4,37 \\
sh_land & $1,16 \pm 0,002$ & 0,57 & 1,24 & 0,00 & 2,23 & 2,23 & $-0,40$ & $-0,93$ \\
\hline
\end{tabular}




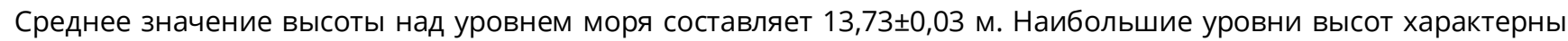
для коренного берега Крыма и Причерноморской низменности. В пределах залива Сиваш высоты рельефа не превышают 14 м над уровнем моря. Распределение высот смещено влево в область меньших значений (рис. 1), о чем свидетельствует позитивные значения индекса асимметрии. Негативный эксцесс свидетельствует о двухвершинном характере распределения значений высот. Один максимум характерен для высот 5-7 м, второй для 20-22 м.

Топографический индекс влажности варьирует от 5,0 до 21,5, в среднем составляя 10,1. Зоны с высоким и низким значением топографического индекса влажности радиально расходятся от водного зеркала залива Сиваш, создавая значительную пестроту режимов влажности на различных дистанциях от уровня воды до отметок высот на плакоре. Распределение значений топографического индекса влажности ассиметрично и двухвершинно.

Индекс топографического положения в среднем равен нулю и варьирует в пределах от -4,1 до 6,5. Асимметрия распределения этого показателя невелика, что указывает на его мономодальный характер. Эксцесс положителен, что указывает на тенденцию преимущества средних значений этого показателя.

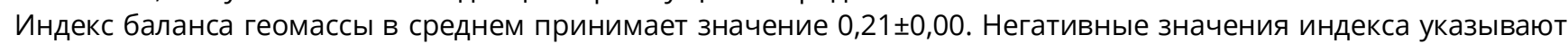
на участки с накоплением геомассы, такие как депрессии рельефа или поймы рек. Позитивные значения указывают на участки с высокой степенью риска эрозионных процессов. Значение индекса, близкое к нулю, указывает на участки с равновесием убыли и прибыли геомассы (Kunakh, Papka, 2016; Moeller et al., 2008). Таким образом, в целом для изучаемой местности характерен определенный риск развития эрозионных процессов. Следует отметить, что распределение индекса баланса геомассы является ассиметричным со сдвигом влево, это говорит о том, что среднее значение дает смещенную (завышенную) оценку средней генеральной совокупности. Зоны с позитивными и негативными значениями индекса баланса геомассы формируют радиали, которые расходятся от зеркала залива вглубь коренного берега.

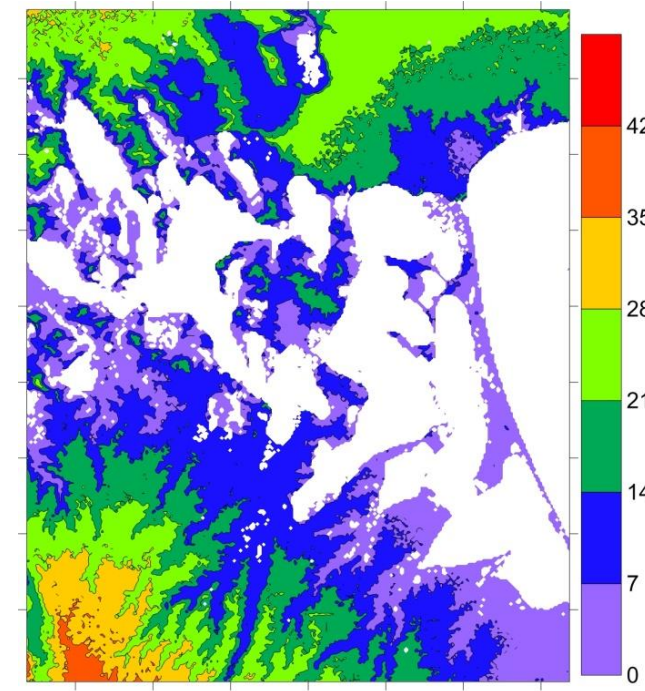

DEM

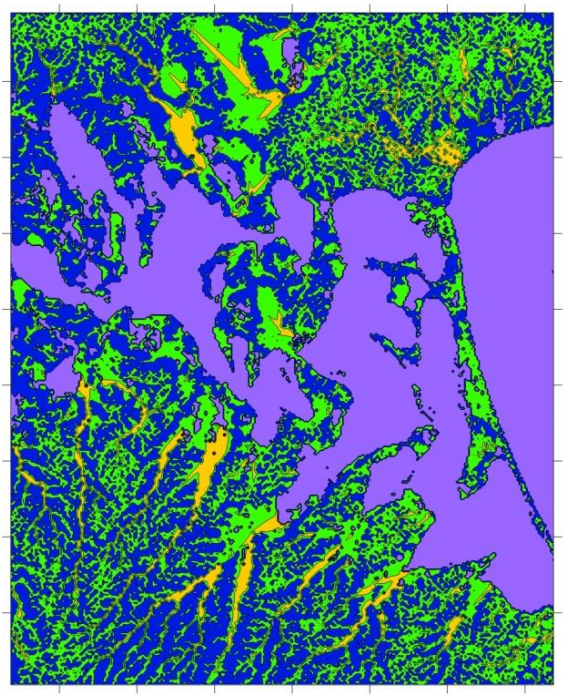

TWI

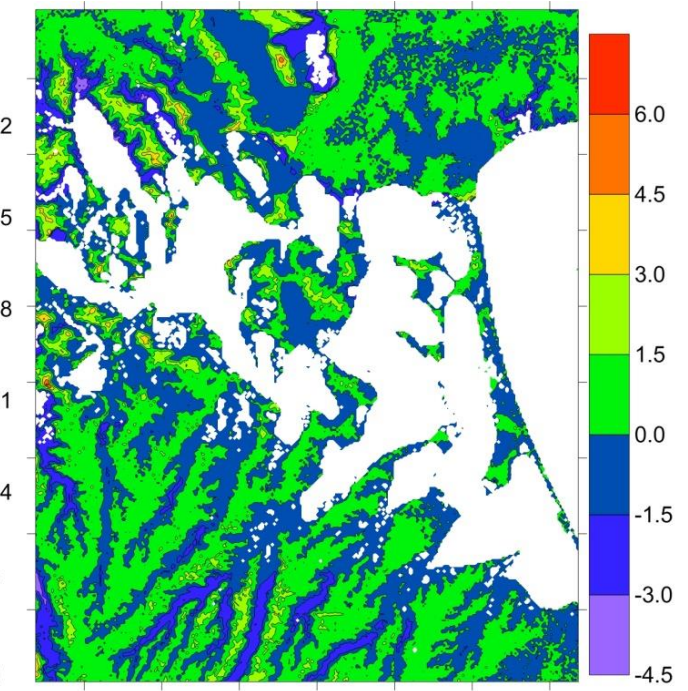

TPI

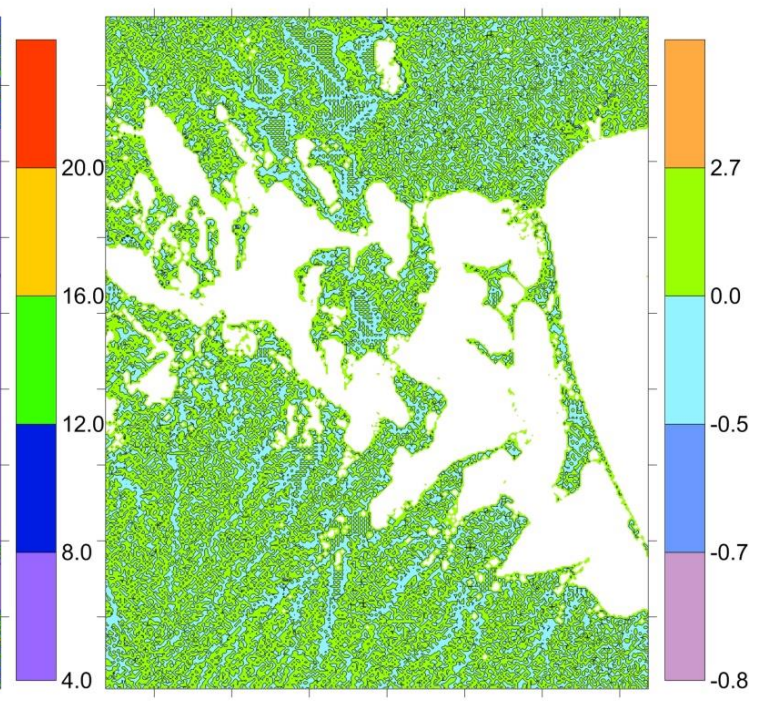

MBI 
Рис. 3. Пространственное варьирование эколого-географических переменных

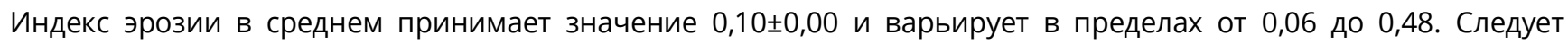
отметить, что в целом для Европы этот показатель составляет 1,63. В странах с самым выровненным рельефом (Нидерланды, страны Балтии, Финляндия) этот показатель в среднем не превышает 0,5 (Panagos et al., 2015). Taким образом, индекс эрозии свидетельствует о в целом не высоком эрозионном потенциале территории. Кроме того, распределение асимметрично со сдвигом к минимальным значениям, а эксцесс имеет высокое положительное значение, что указывает на приоритет модальных уровней данного показателя. Тем не менее, пространственное размещение указывает на приуроченность участков с повышенными значениями индекса эрозии к прибрежным участкам, что позволяет предположить структурирующую роль активности эрозионных процессов в формировании разнообразия местообитаний водоплавающих птиц.

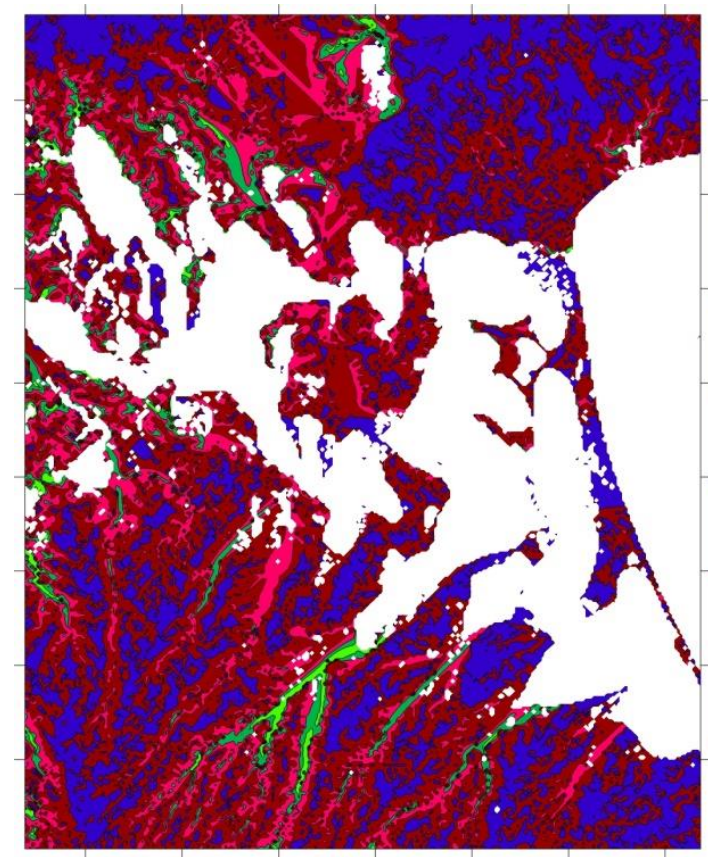

LS

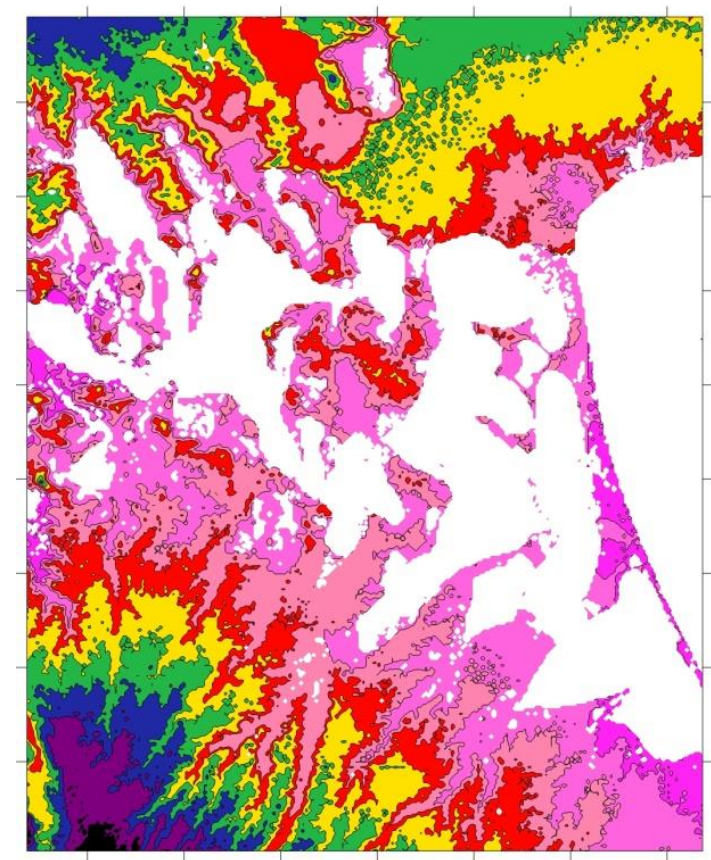

Diff

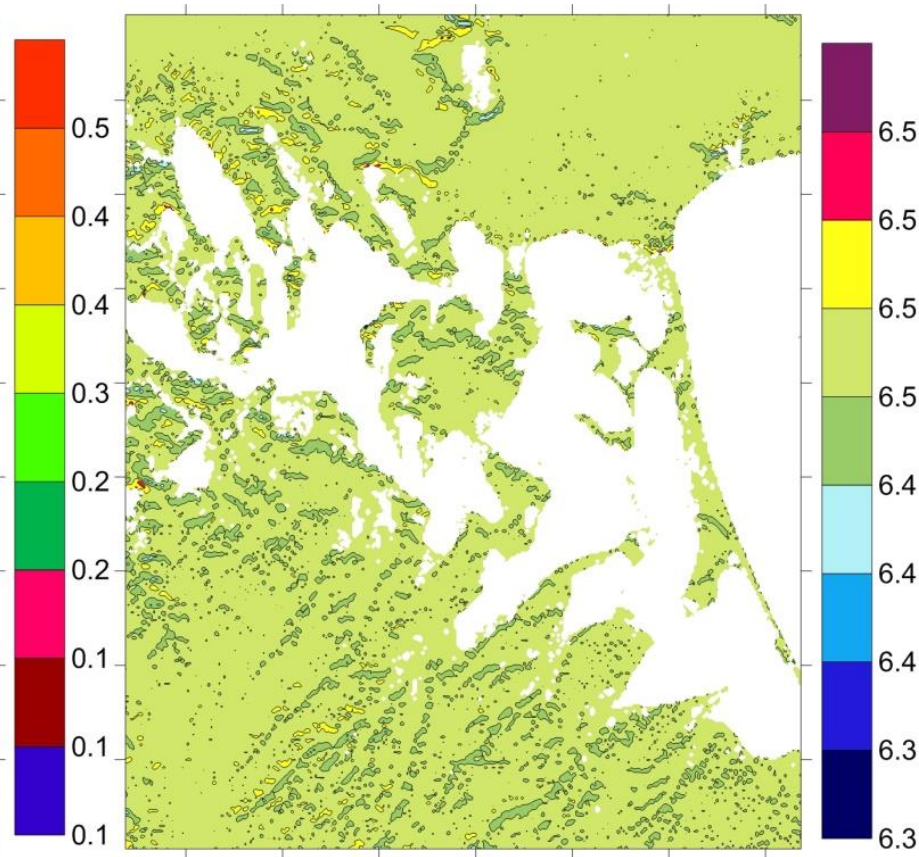

Dir

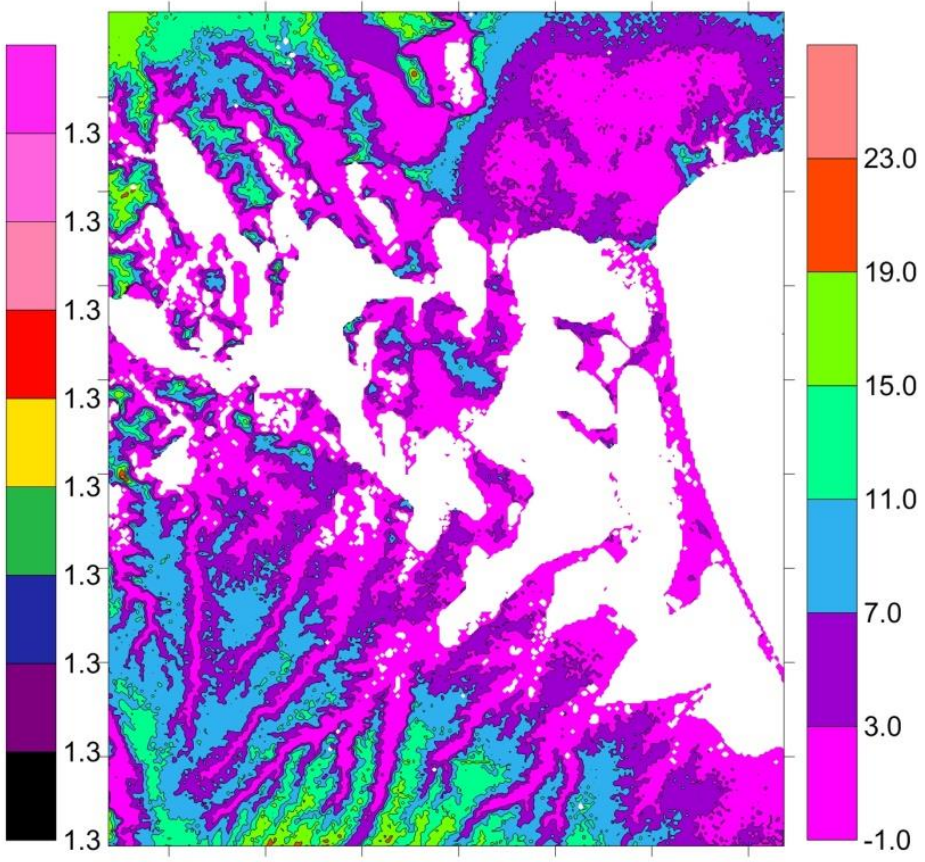

Vert

Рис. 4. Пространственное варьирование эколого-географических переменных 


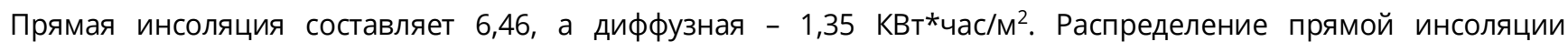
характеризуется тенденцией преимущества модального значения, что обусловлено в целом открытым характером местности. Для диффузной инсоляции характерна гистограмма, смещенная вправо к большим значениям.

Пространственное варьирование прямой инсоляции не формирует четко выраженных паттернов. Для непрямой инсоляции можно отметить большую обеспеченность солнечной энергией прибрежных территорий. Распределение солнечной энергии имеет важное значение именно в зимний период времени, так как влияет на динамику климатических процессов, таких как образование ледовой корки и её таяние, что не может не влиять на качество кормовых свойств угодий, где проходит зимовка птиц.
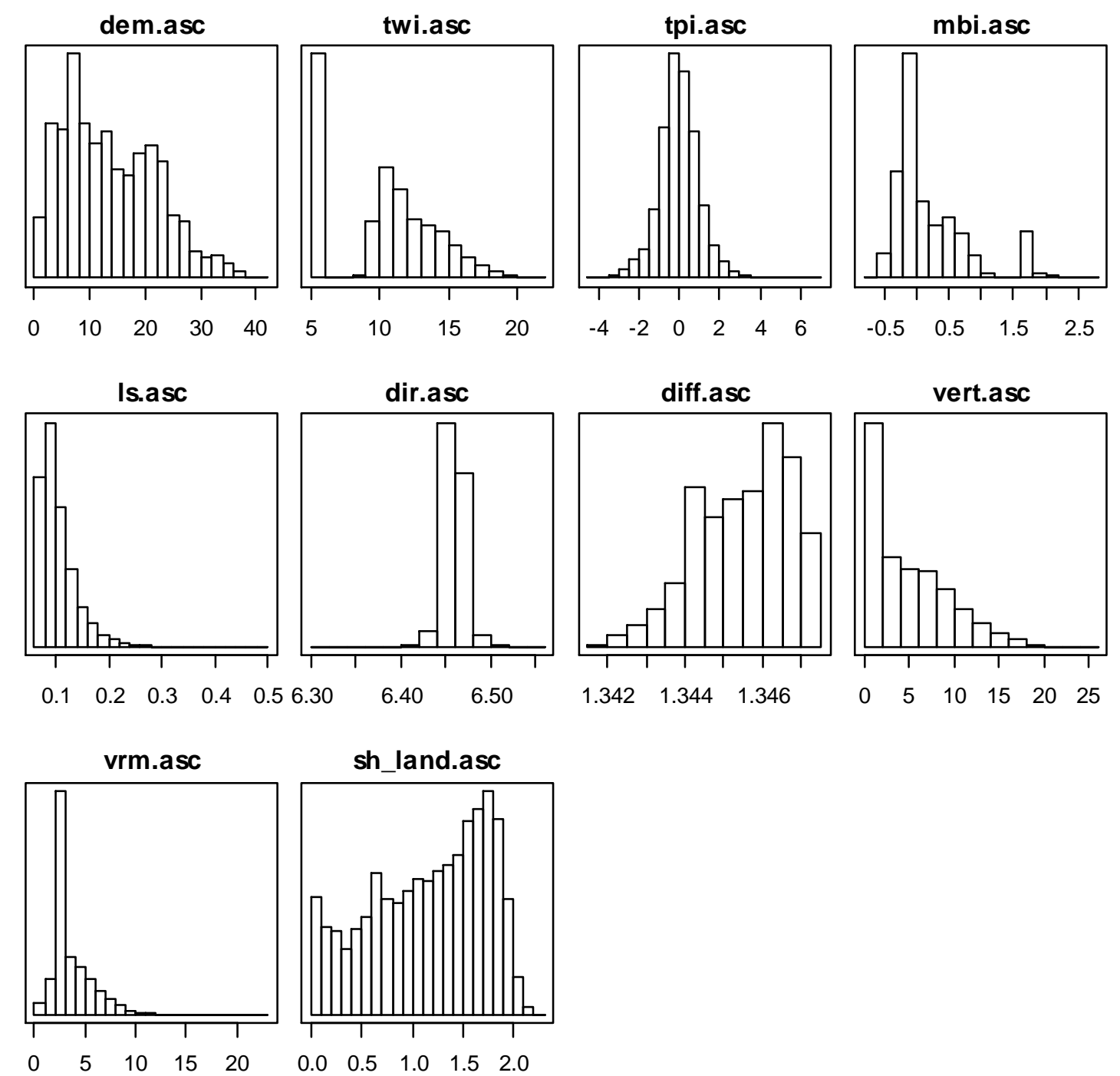

Рис. 5. Гистограммы распределения эколого-географических переменных

Высота над русловой сетью или вертикальная дистанция до русловой сети в среднем составляет 4,72 $\pm 0,01 \mathrm{~m} \mathrm{и}$ варьирует от 0,00 до 22,73 м. Этот геоморфологический показатель как маркер уровня грунтовых вод имеет важное информационное значение для отображения гидроморфной поясности ландшафтов Присивашья (Leontyev, Leontyev, 1956; Pozachenyuk, 1986; Mikhaylov, 2006). Пояс недренированных равнин занимает 24,10\% территории полигона, или 31,33 \% территории Присивашья (условная граница принята для тех территорий, высота грунтовых вод которых не превышает 8 м).

Пояс слабодренированных равнин составляет 20,17 \% территории полигона или 26,22 \% территории Присивашья. Пояс относительно дренированных лессовых равнин составляет 32,65 \% от территории полигона или $42,45 \%$ от территории Присивашья. Площадь территории, которая соответствует коренному берегу и плакору, составляет 23,08 \% от площади полигона. Необходимо отметить, что различные участки гидроморфной поясности, которые представляют экологически существенно различные условия для жизни живых организмов, формируют весьма пеструю мозаику. В рамках этой мозаичности недренированные равнины могут проникать на значительное расстояние от уреза воды залива, тогда как участки с дренированным режимом могут находится в непосредственной близости к побережью. 
Векторная мера пересеченности местности оценивает дисперсию ортогональных к поверхности рельефа векторов и является мерой пересеченности местности. Пересеченность понимается как негладкость поверхности (Sappington et al., 2007). Распределение этой переменной несимметричное и смещено в левую часть, о чем также свидетельствует позитивное значение асимметрии. Среднее значение пересеченности местности составляет 3,76 0,01 и варьирует от нуля до 22,7. Значительный позитивный эксцесс указывает на стремление значений меры пересеченности к модальному значению.

Анализируя полученные результаты, можно сказать, что в целом равнинная местность Присивашья не является пересеченной, однако в отдельных случаях перепады высот довольно крутые; при этом небольшие по абсолютной высоте, но обрывистые берега, могут создавать пересеченность местности с соответствующей вариабельностью экологических режимов. Это обстоятельство на фоне общей экстремальности условий зимовки птиц может оказывать существенное влияние на их пространственное размещение.

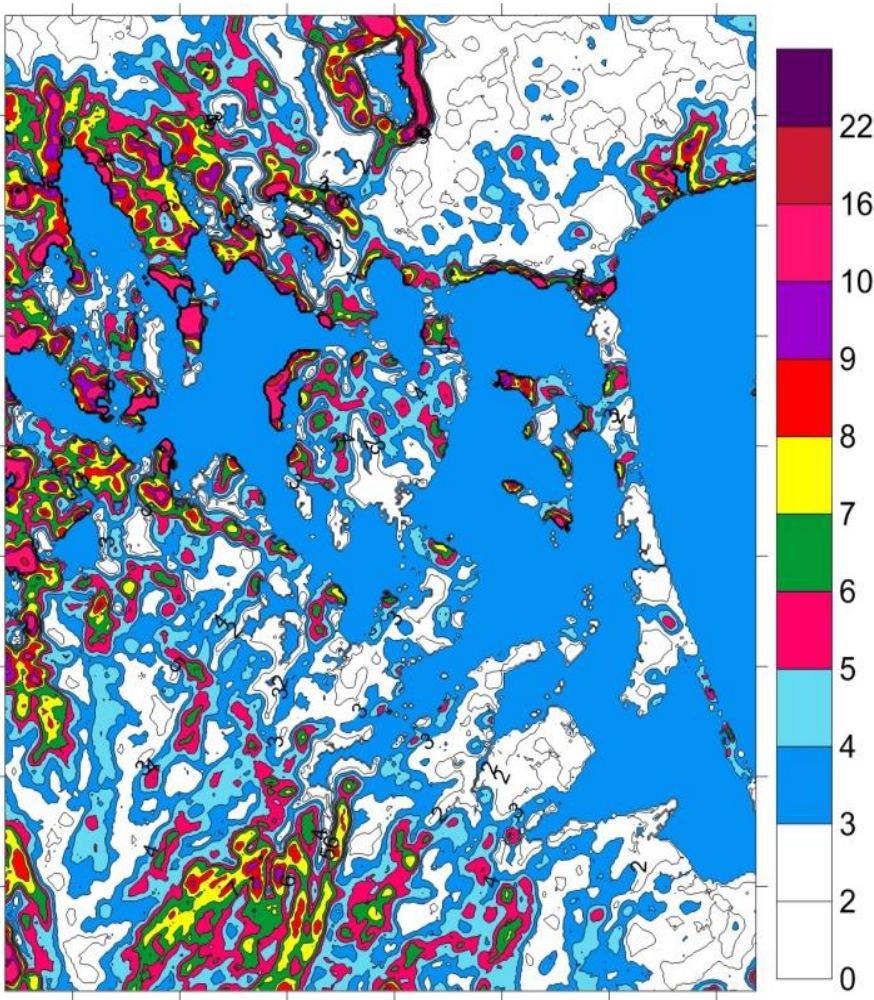

VRM

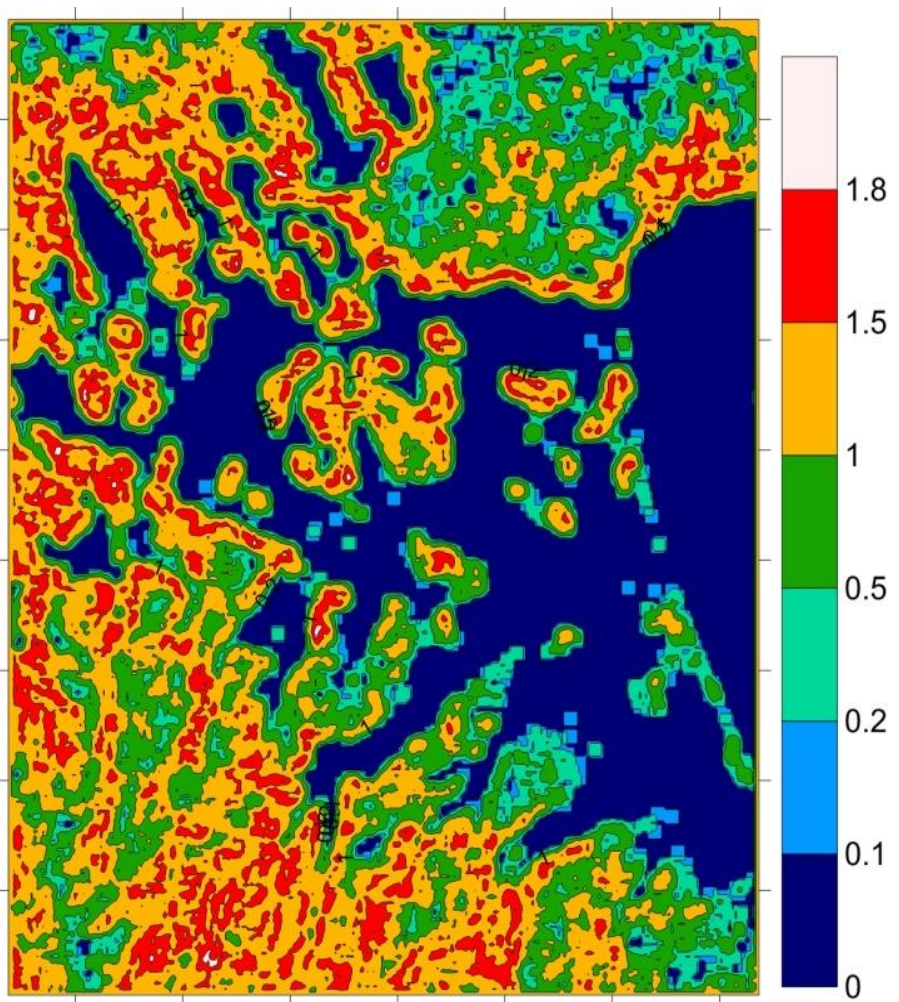

SH_Land

Рис. 6. Пространственное варьирование эколого-географических переменных

Помимо континуальных характеристик рельефа его можно охарактеризовать с помощью дискретных форм рельефа. Нами формы рельефа выделены на основе индекса шероховатости по Райли и coaвт. (Riley et al., 1999) (рис. 1). Проведенный анализ позволил выделить 10 форм рельефа. Преобладающей формой рельефа является равнина, которая занимает 57,9 \% поверхности суши изучаемого полигона. Значительно меньшую дол поверхности занимают поды и лиманы (8,3%), холмы и гребни (7,9\%) и верхние участки склонов (6,3 \%). Прочие формы рельефа занимают очень малую часть поверхности суши полигона.

Формы рельефа создают разнообразие поверхности Земли, которое можно количественно оценить с помощью индекса Шеннона. Разнообразие отдельных сайтов с окном пропускания 2 пикселя, что можно

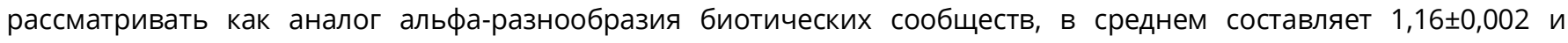
варьирует в пределах от нуля до 2,23.

На рис. 7 представлены общие и частные распределения эколого-географических переменных. Под частными понимаются распределения значений переменных, где было установлено присутствие птиц. Совпадение или очень близкое совпадение указывает на то, что данная переменная не принимает участия в определении свойств экологической ниши птиц. Напротив, отклонения указывают на структурирующую роль переменной. Количественный аспект структурирующего значения переменных представлен в табл. 1. Соотношения общего и частного распределений количественно охарактеризованы с помощью таких показателей экологической ниши, как маргинальность и специализация.

Интегральное отображение экологической ниши в пространстве маргинальности и первой оси специализации показано на рис. 8. Этот рисунок свидетельствует о том, что геоморфологические переменные в качестве экологогеографических предикторов несут значительную информацию о экологической нише лебедя-шипуна на зимовке. Из значительного множества условий животные выбирают стации с определенным перечнем условий. 


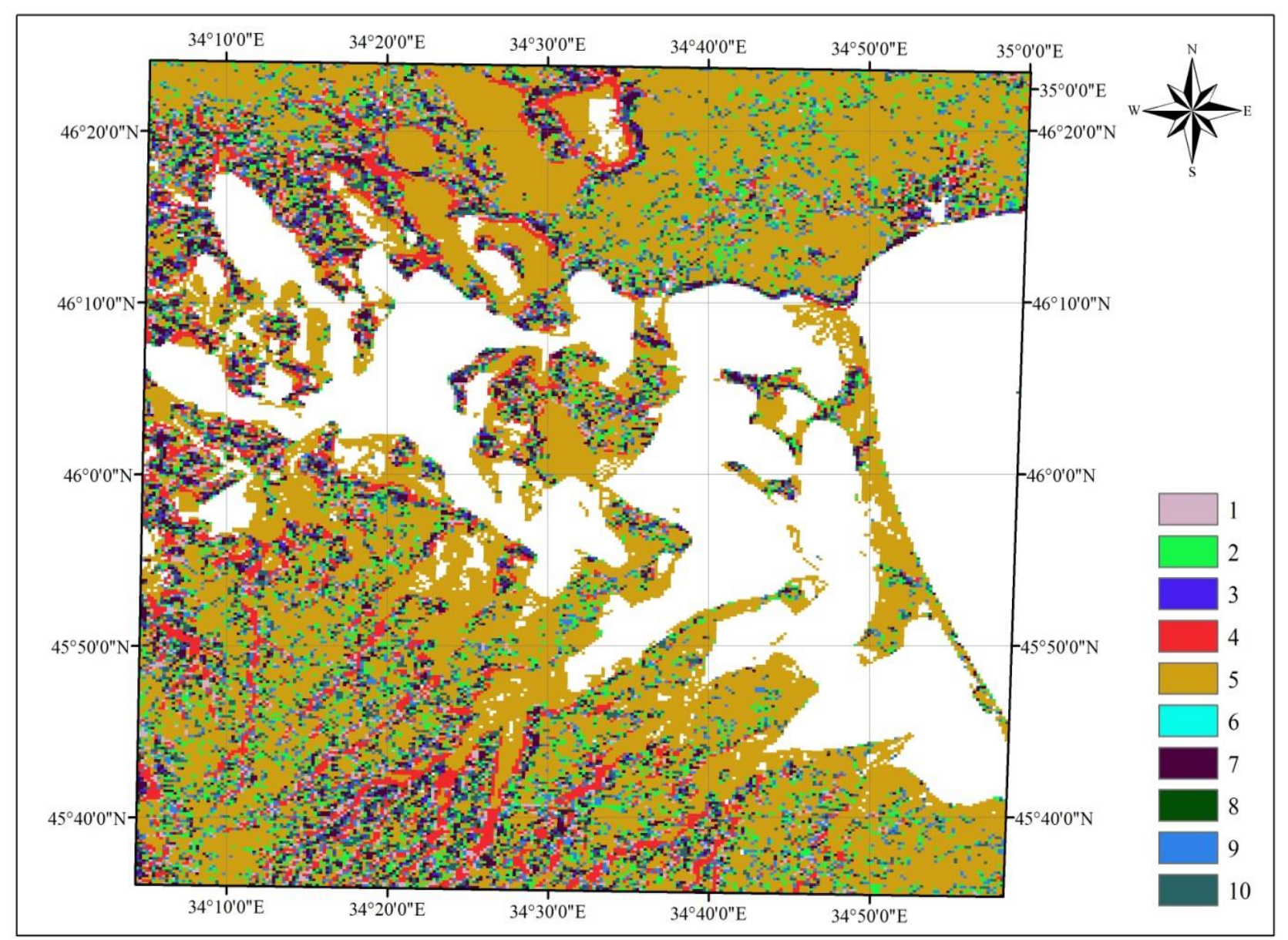

Рис. 7. Пространственное распределение форм рельефа на основе индекса шероховатости по Riley et al. (1999). Условные обозначения. 1 - узкие водные потоки; 2 - широкие поймы (лиманы) и поды; 3 - узкая пойма; 4 долина; 5 - равнина; 6 - открытый склон; 7 - верхний склон; 8 - локальные гребни, холмы в долинах; 9 - малые холмы; 10 - большие холмы, гребни

Как показал пермутационный тест, оси маргинальности (Mar =9,78, $p=0,04)$ и специализации 1-4 (Spe $1=50,57$, $\left.p=0,04, \mathrm{Spe}_{2}=8,38, p=0,04, \mathrm{Spe}_{3}=7,02, p=0,04, \mathrm{Spe}_{4}=2,98, p=0,04\right)$ статистически достоверно отличаются от случайной альтернативы.

Анализ табл. 2 указывает, что маргинальность всех представленных континуальных эколого-географических переменных не велика. Наибольшей маргинальностью характеризуются категориальные переменные, которые указывают на различные формы рельефа. Наибольшим предпочтением отличаются открытые склоны. Континуальные переменные дополняют особенности этих стаций. Открытые склоны, закономерно, характеризуются большим фактором эрозии, находятся в более пересеченной местности и в условиях большего геоморфологического разнообразия местности.

Континуальные переменные характеризуются большим значением в определении специализации экологической ниши лебедя-шипуна. Ось специализации 1 указывает на то, что лебеди-шипуны отдают предпочтения стациям, которые находятся в узком диапазоне высот рельефа и режима диффузной инсоляции. Ось специализации 2 чувствительна к высоте рельефа, индексу топографического положения, вертикальной дистанции до русловой сети, а также к пространственному размещению таких форм рельефа, как локальные гребни и холмы, а также поймы, лиманы и поды.

Ось специализации 3 отражает значении в структурировании экологической ниши таких предикторов, как высота рельефа, диффузная инсоляция и широкие лиманы и поды. Ось специализации 4 также чувствительна к высоте рельефа, диффузной инсоляции и пространственному размещению малых холмистых возвышений.

Количественная характеристика экологической ниши позволяет сделать оценку индекса предпочтения местообитаний (рис. 1). Этот индекс указывает на участки, которые обладают геоморфологическими свойствами, наиболее предпочтительными для лебедя-шипуна во время зимовки.

Анализ полученных данных с одной стороны приводит нас к тривиальными результатам - лебедь-шипун как водоплавающая птица встречается в биотопах, наиболее приближенных к водному зеркалу залива Сиваш. Нетривиальным результатом является то, что не все прибрежные участки одинаково предпочтительны для лебедя-шипуна. 


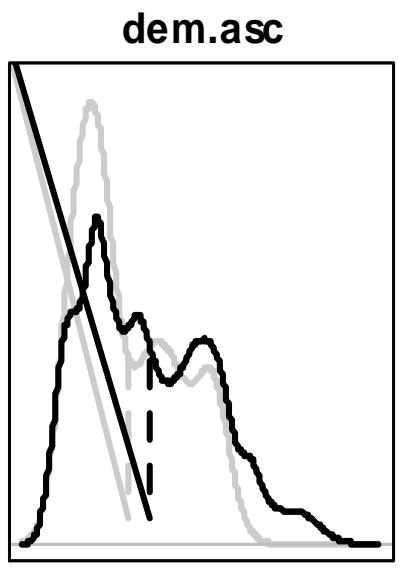

Is.asc

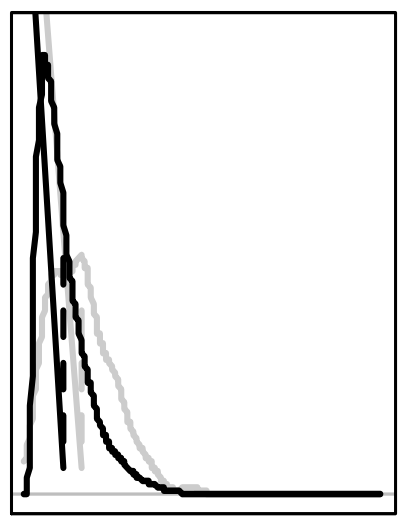

vrm.asc

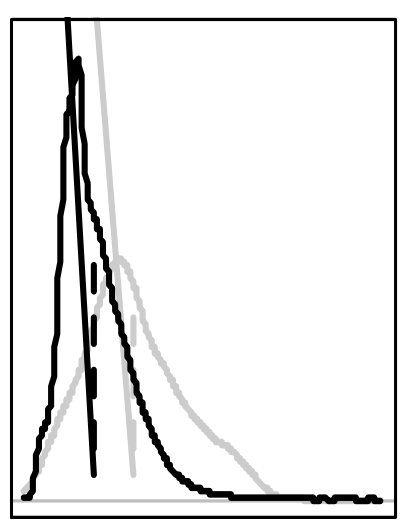

twi.asc

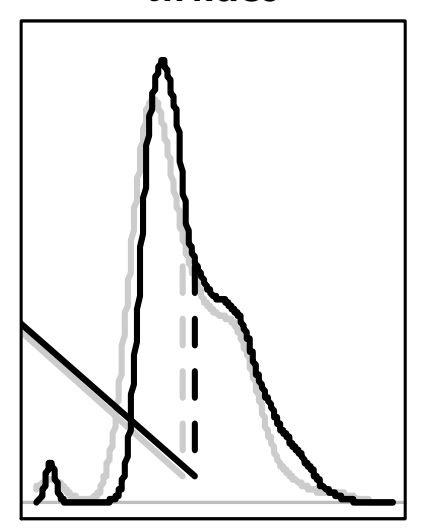

dir.asc

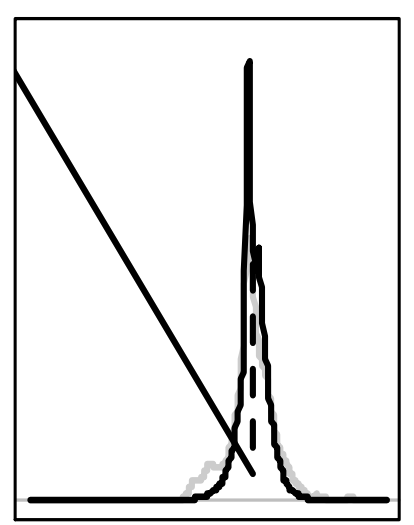

sh_land.asc

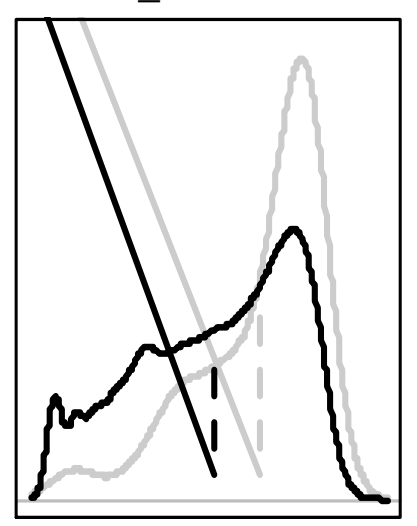

tpi.asc

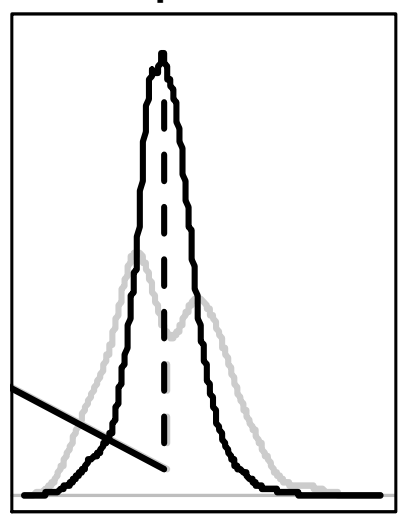

diff.asc

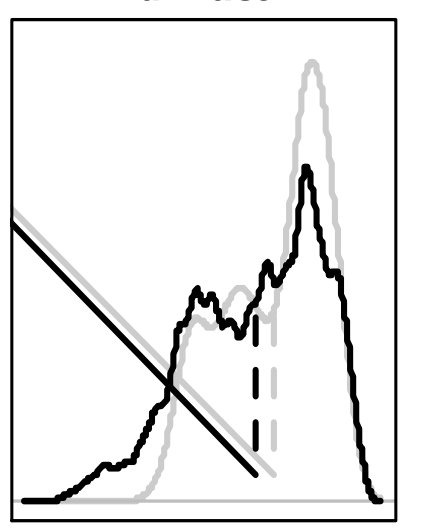

landforms.asc

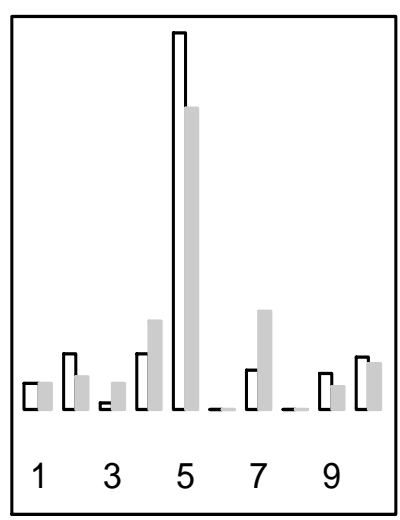

mbi.asc

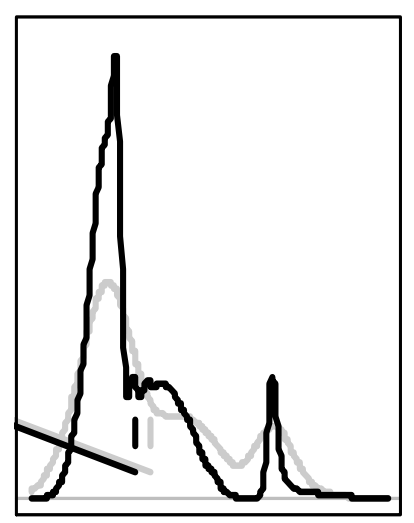

vert.asc

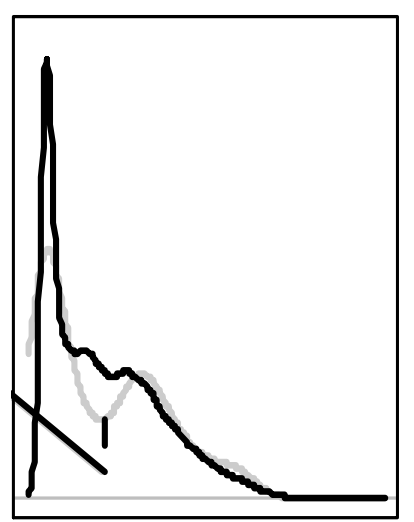

Рис. 8. Общие (черная линия) и частные (серая линия) распределения эколого-географических переменных

Оптимальные геоморфологические условия для зимовки лебедя присущи для северной части косы Арабатская Стрелка, для полуостровов Семеновский угол, Чонгар (южная часть полуострова менее предпочтительна), заливы западного Присивашья. Прибрежные территории южной части Присивашья оказываются менее благоприятными для зимовки лебедя-шипуна.

Следует отметить, что полученный результат относится к оценке глобальной ситуации в пределах изучаемого полигона. Результаты анализа зависят не только от учета точек присутствия и от размещения точек псевдоотсутствия. В глобальном варианте анализа такими точками псевдоотсутствия являются все прочие точки территории, которые не отнесены к точкам присутствия.

Иначе говоря, субъективный выбор крайних границ изучаемого полигона оказывает некоторое влияние на итоговый результат оценки свойств экологической ниши. Это обстоятельство подтверждается значительной отдаленностью формы экологической ниши от элипсоидной, которая соответствует классическим представлениям о конфигурации экологической ниши и на поиск которой направлен ENFA-анализ.

Однако нельзя исключать и других причин сложной конфигурации экологической ниши, к которым можно отнести гетерогенность популяции лебедя-шипуна на зимовке. 


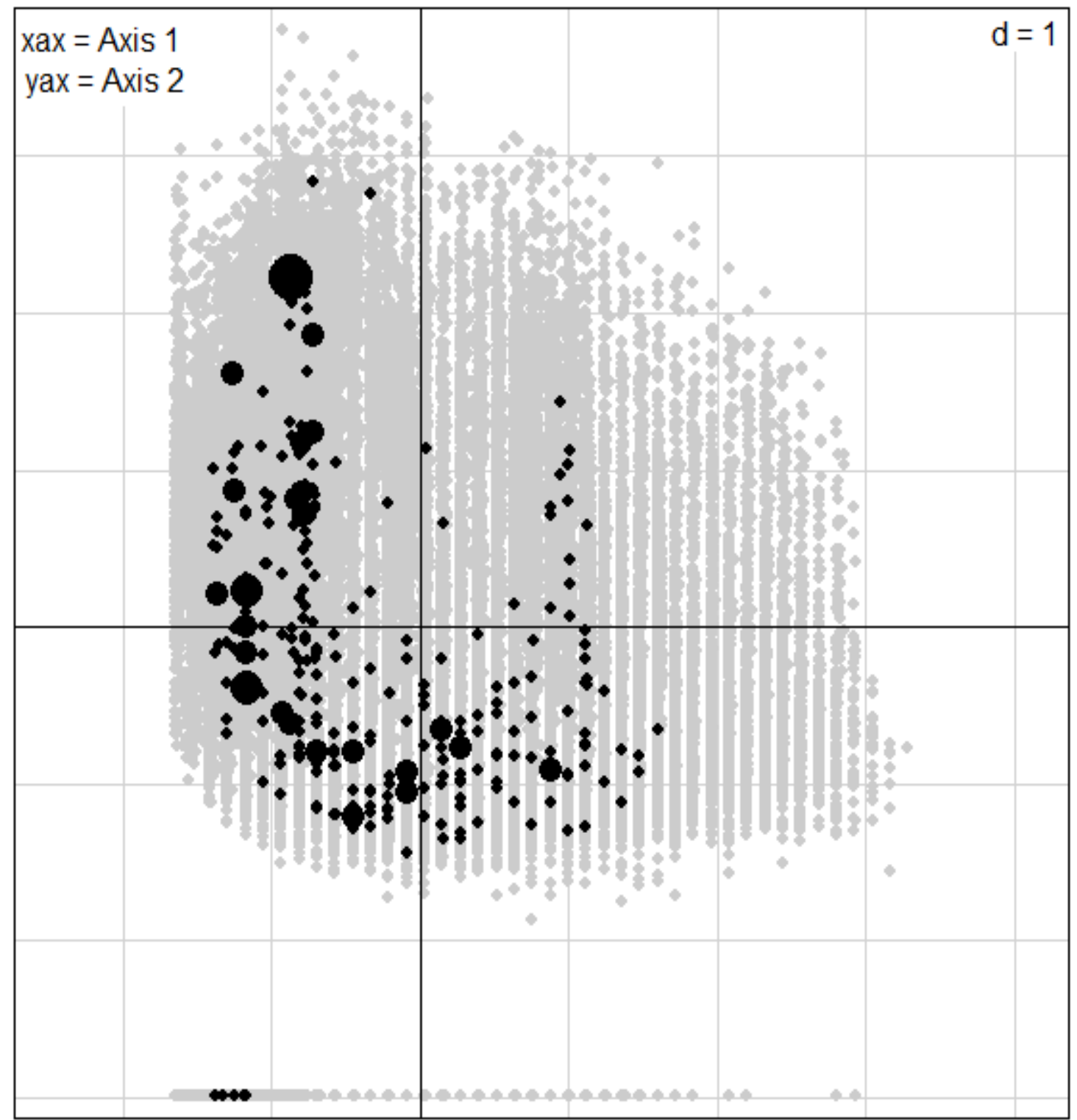

Рис. 9. Отображение экологической ниши лебедя-шипуна. Светло-серая область - пространство экологогеографических переменных, серая область - экологическая ниша. Ось абсцисс - маргинальность, ось ординат специализация.

Для учета масштабной компоненты экологической ниши нами применена методика дифференциального окна пропускания для определения размещения точек псевдоотсутствия (Жуков и др., 2015). Нами варьировалось максимальное расстояние от точек присутствия лебедя шипуна для случайного размещения точек псевдоотсутствия. Дистанции варьировали от 270 м до 27 км (всего 30 дистанций, интервалы равные в логарифмическом масштабе). Для каждой дистанции рассчитывались параметры экологической ниши и достоверность отличия этих параметров от нулевой альтернативы на основе пермутационного теста.

Маргинальность и специализация оси 1 с увеличением окна пропускания демонстрируют монотонное увеличение своих показателей (рис. 1). Маргинальность статистически достоверно начинает отличаться от случайной альтернативы начиная с окна пропускания 1000 м. Ось специализации достигает достоверно отличного от нулевой альтернативы состояния начиная с окна пропускания 2000 м. Однако это состояние не является устойчивым. Свойства специализации экологическая ниша устойчиво приобретает только начиная с дистанции $6000 \mathrm{~m}$.

В изученном диапазоне окна пропускания маргинальность и специализация экологической ниши по отдельным эколого-географическим переменным существенно изменяется. Маргинальность экологической ниши по высоте рельефа при малых интервалах окна пропускания (до 1200 м) имеет отрицательное значение, что свидетельствует о предпочтении лебедями локальных понижений в указанном диапазоне расстояний.

При окнах пропускания 1200-1600 м маргинальность становится позитивной, а при превышении окна 1600 снова негативной. Таким образом, мы наблюдаем качественную перестройку роли высоты рельефа как важного аспекта структурирования экологической ниши лебедя-шипуна в зависимости от масштаба рассмотрения. 
Таблица 2. Структура экологической ниши лебедя-шипуна

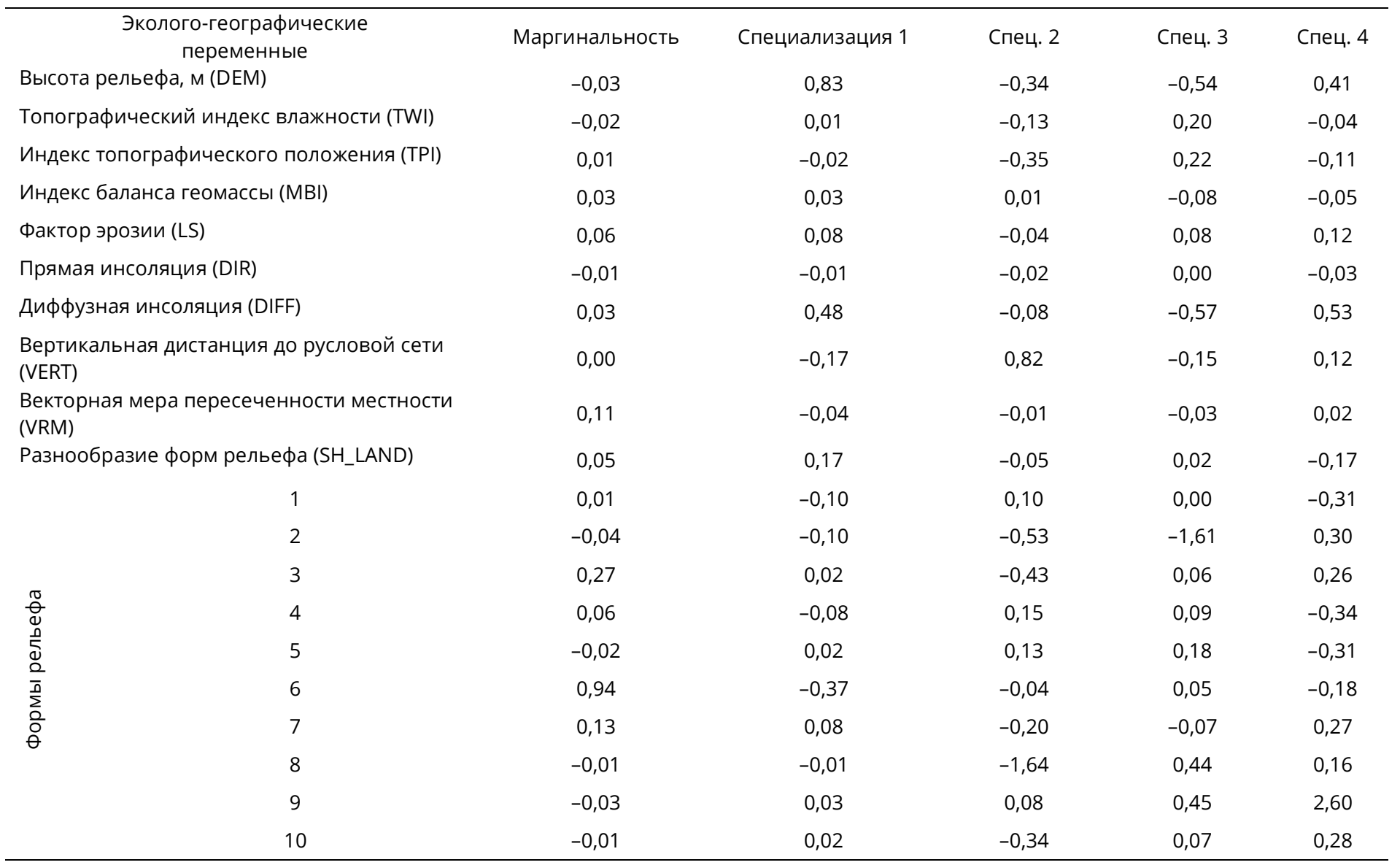

Для топографического индекса влажности характерна отрицательная маргинальность. Всплеск, для которого отмечена позитивная маргинальность относится к области с недостоверным отличием от случайной альтернативы. Отрицательная маргинальность индекса TWI указывает на предпочтение лебедем-шипуном дренированных стаций на суше. Индекс топографического положения преимущественно имеет позитивную маргинальность, что указывает на предпочтение лебедями-шипунами элементов рельефа с выпуклой поверхностью. Индекс баланса геомассы в условиях в целом равнинного рельефа не является существенным для дифференциации экологической ниши лебедя-шипуна.

Маргинальность фактора эрозии при граничном окне пропускания 600 м переходит из негативной в позитивную область. Это свидетельствует о том, что в рамках ландшафта лебеди-шипуны выбирают местообитания с изрезанным рельефом, где вероятность эрозионных процессов в целом выше, чем в среднем по окружающей территории. Но, в рамках указанных локалитетов предпочитаемыми оказываются микроучастки с меньшей вероятностью эрозии.

Маргинальность прямой инсоляции имеет отрицательное значение только при малых значениях окна пропускания, которые находятся в зоне статистической недостоверности. Для основной части диапазона окон пропускания маргинальность имеет позитивные знаки. Начиная с окна пропускания 1600 м и более маргинальность этого показателя практически не изменяется.

Таким образом, лебеди-шипуны предпочитают участки с большим уровнем прямой солнечной инсоляции. Для диффузной инсоляции отмечена обратная зависимость: лебеди-шипуны предпочитают участки с меньшим уровнем диффузной инсоляции.

Наибольшая маргинальность по модулю характерна для диффузной инсоляции при окнах пропускания 400600 м. Наибольшее количество прямой солнечной радиации, как известно, приходит на склоны южных экспозиций. Распределение рассеянной радиации иное, поскольку потоки идут по отношению к граням рельефа по-другому. Она максимальна на водоразделах, меньше на днище долины и минимально на крутых склонах, причем как на склонах северной экспозиции, так и на склонах южной экспозиции (Bokov, 2014).

Вертикальная дистанция до русловой сети, как отмечалось является информационно ценным маркером для описания ландшафтной дифференциации в условиях Присивашья. Маргинальность этого показателя для экологической ниши лебедя-шипуна является в целом позитивной, испытывая локальную инверсию в негативную область в диапазоне окна пропускания 1200-2500 м.

Это обстоятельство ещё раз подчеркивает притяжение этого вида к локальным поднятиям рельефа. 


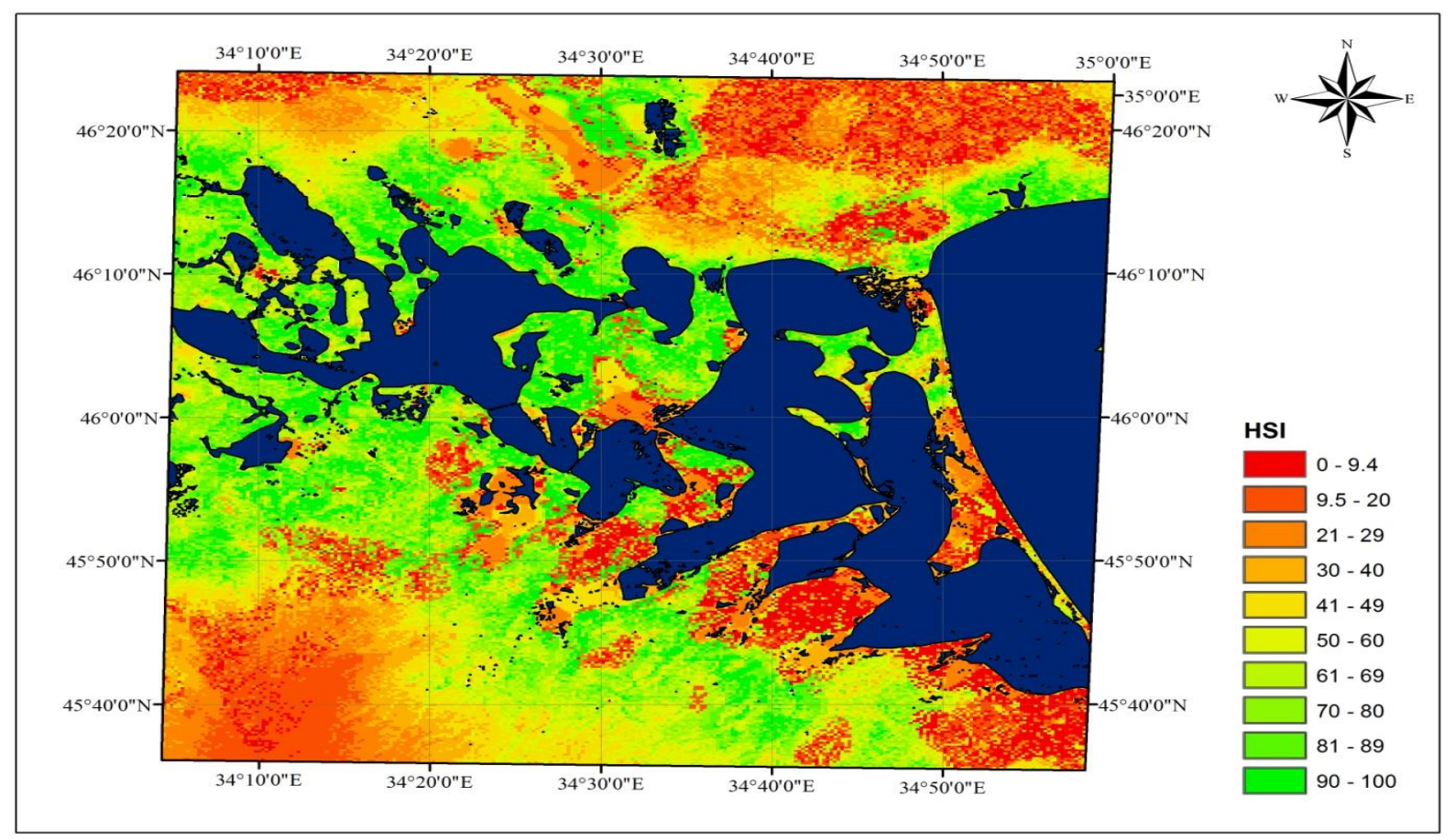

Рис. 10. Индекс предпочтения местообитаний

Векторная мера пересеченности местности при окнах пропускания, превышающих 2500 м, практически мало зависит от эффекта масштаба, оставаясь на позитивном уровне. При меньших значениях окна пропускания маргинальность этого показателя существенно варьирует. Таким образом, в условиях зимовий лебедь-шипун предпочитает преимущественно негладкий рельеф местности.

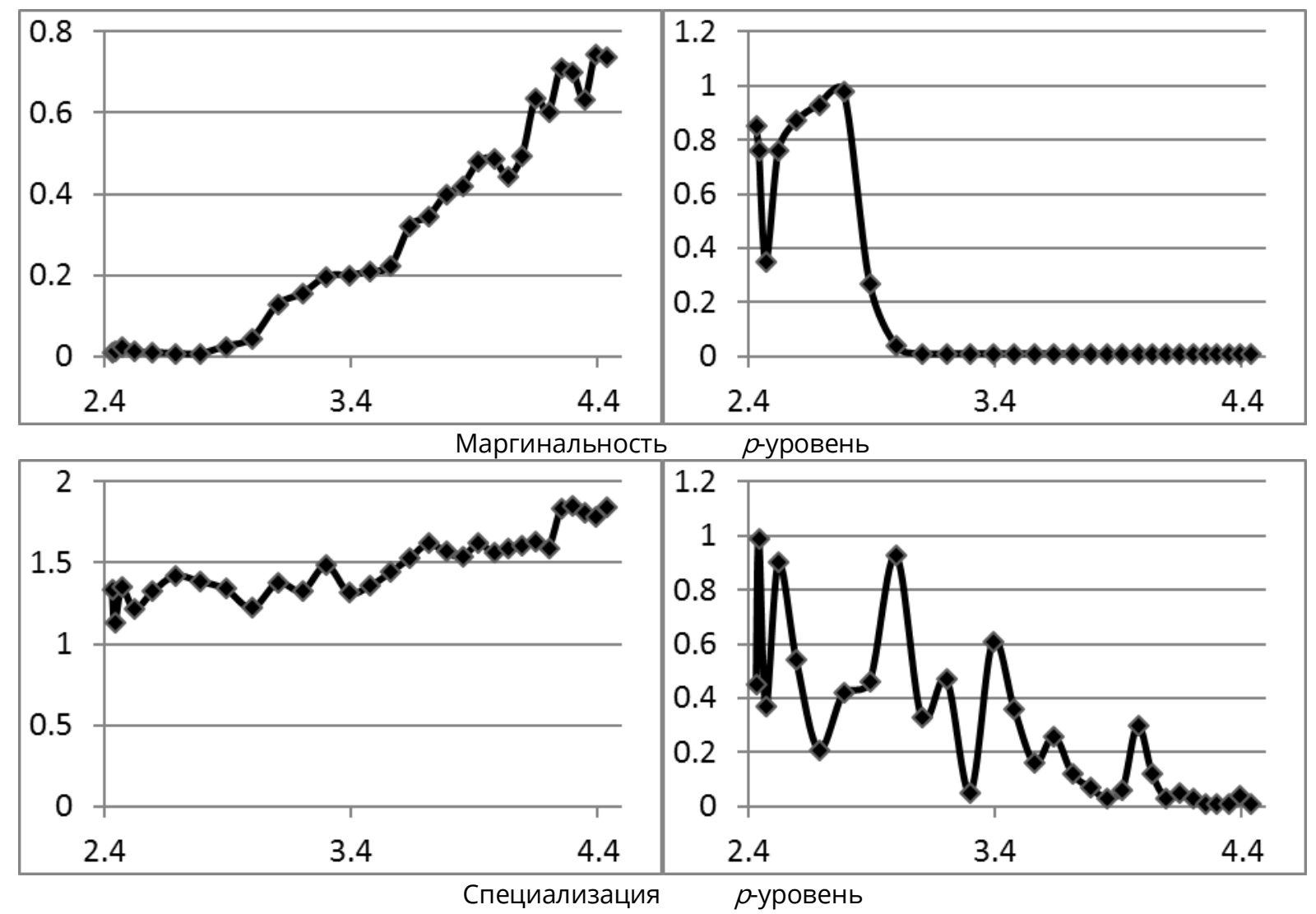

Рис. 11. Варьирование маргинальности, специализации и их статистической значимости в зависимости от ширины окна пропускания 
Важным является маргинальность интегральной метрики - геоморфологического разнообразия. Для малых окон пропускания, которые находятся в области недостоверного отличия от случайной альтернативы, маргинальность является отрицательной. В основном же, маргинальность геоморфологического разнообразия является высокой и позитивной. Таким образом, сочетание разнообразных рельефных форм создает наиболее благоприятные условия для зимовки лебедя-шипуна. По отношению к высоте рельефа экологическая ниша является в высокой степени специализированной - животные предпочитают довольно узкий диапазон высот, при этом такая особенность характерна для всех окон пропускания. Специализация по топографическому индексу влажности демонстрирует значительные колебания при изменениях окна пропускания, что указывает на существенную стохастическую компоненту в наблюдаемом результате.

Специализация по индексу топографического положения увеличивается при возрастании окна пропускания. Для индексов баланса геомассы, фактора эрозии, векторной меры пересеченности местности, прямой и диффузной инсоляций специализация экологической ниши в целом невелика. Только для окон пропускания в районе 700-1000 м наблюдаются спорадические вспышки значений специализации. При этом также нельзя исключить случайного характера такого результата. По признаку вертикальной дистанции до русловой сети экологическая ниша является крайне специализированной. Специализация геоморфологического разнообразия демонстрирует тренд по увеличению при увеличении окна пропускания, однако этот тренд сопровождается значительными флуктуациями. 

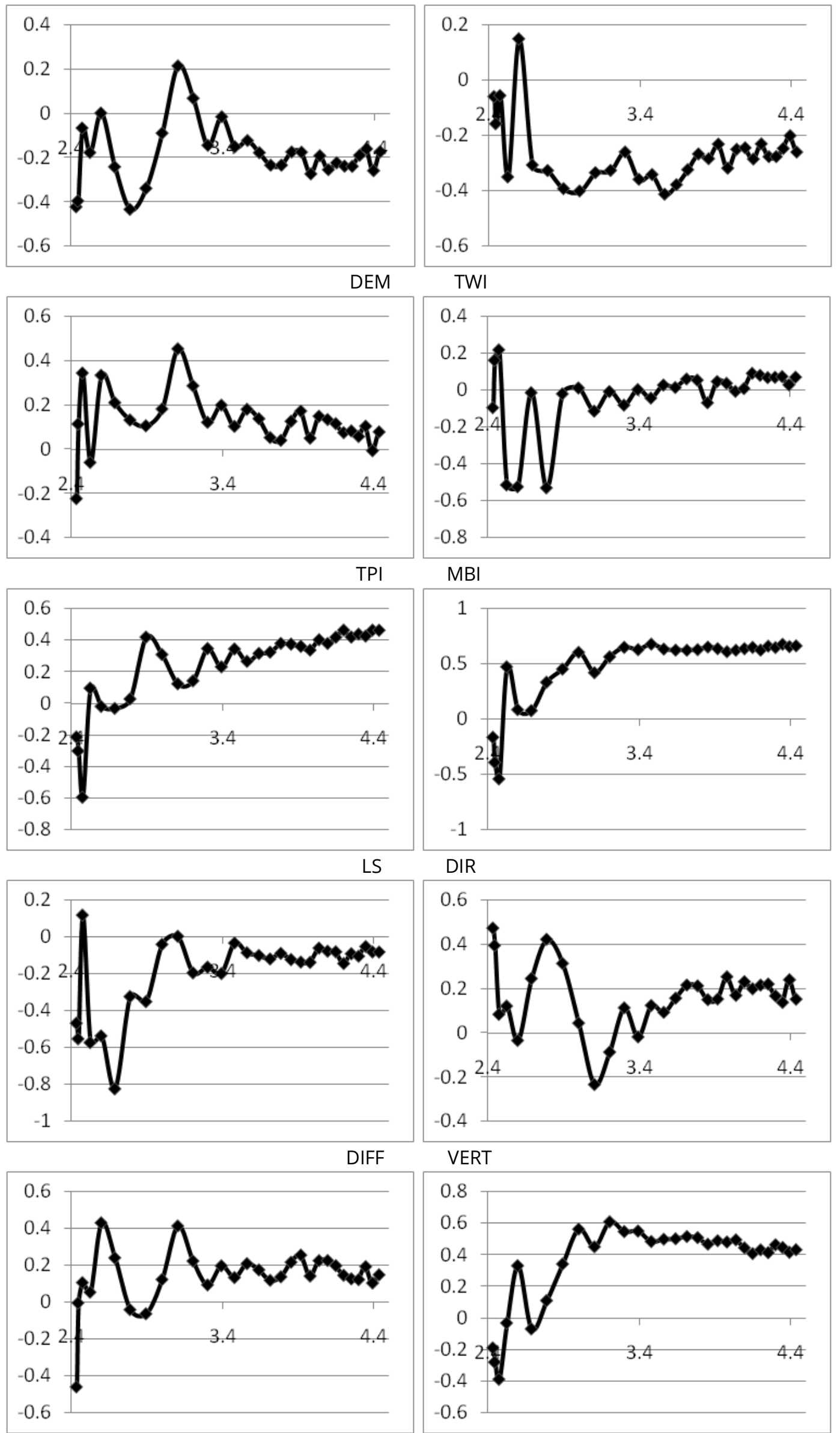

VRM
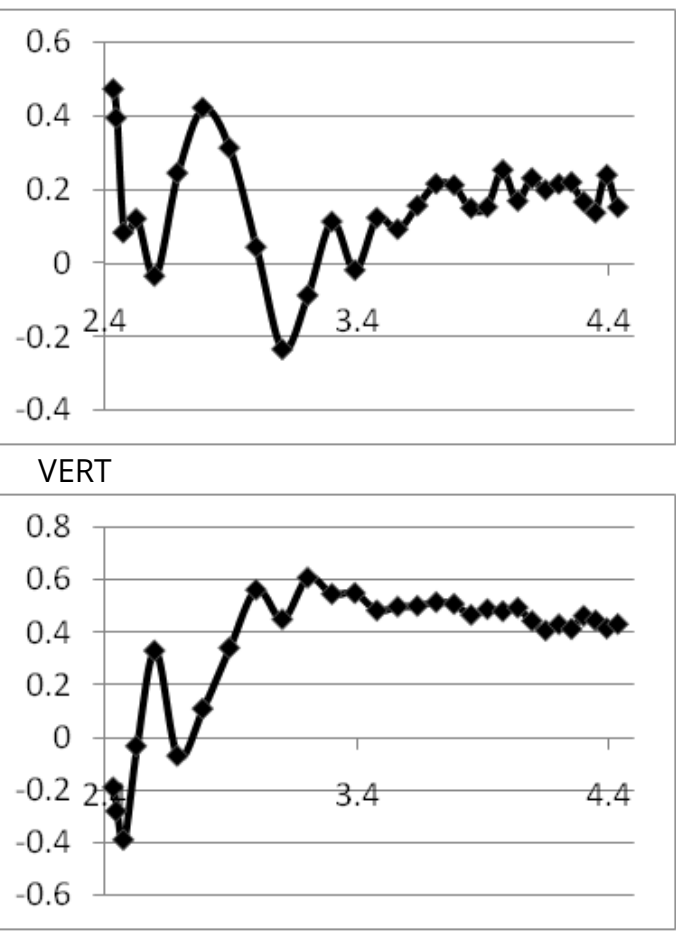

Рис. 12. Варьирование маргинальности эколого-географических переменных в зависимости от ширины окна пропускания 


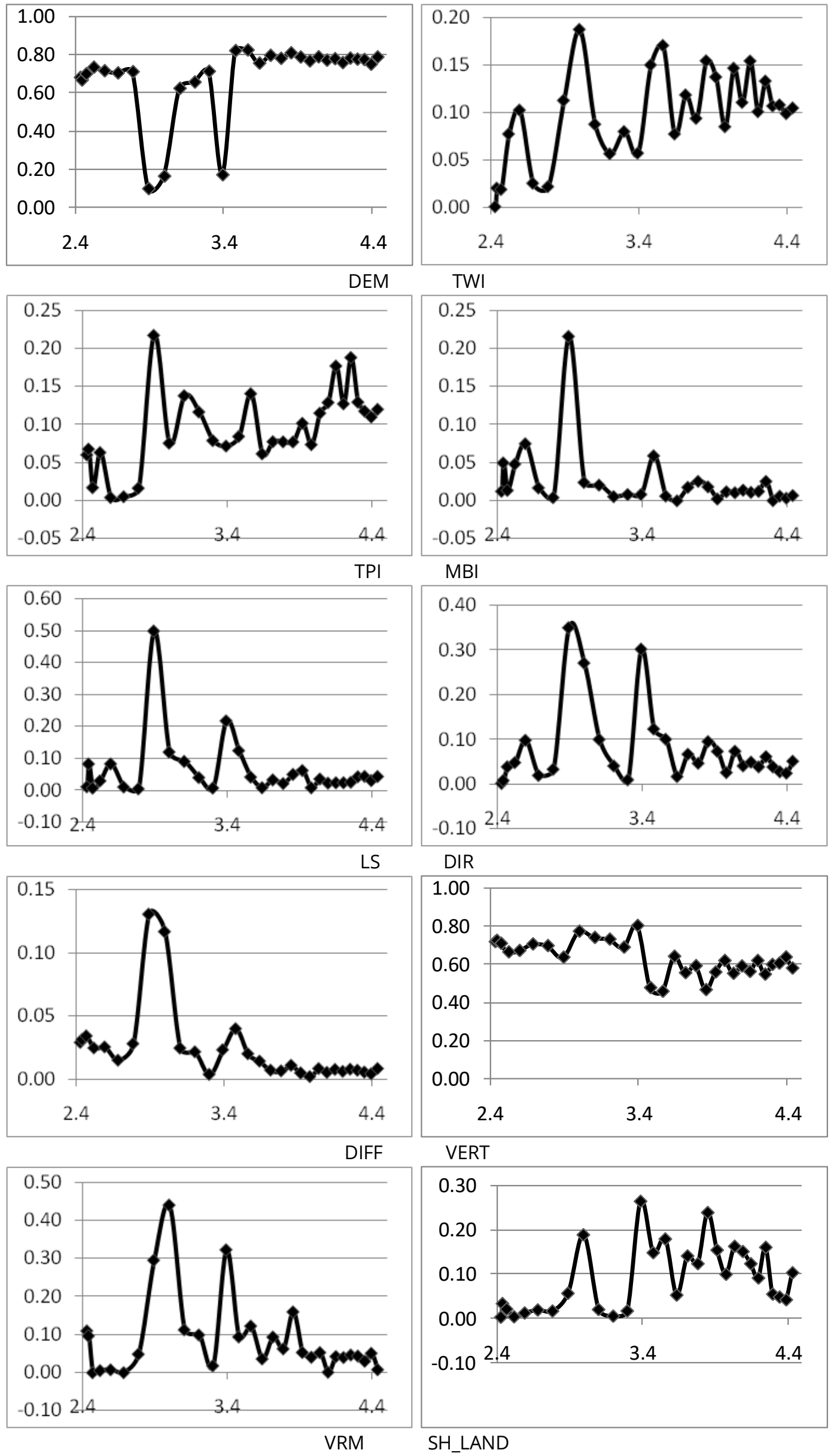

Рис. 13. Варьирование специализации эколого-географических переменных в зависимости от ширины окна пропускания 
Факторный анализ экологической ниши позволяет оценить свойства экологической ниши исходя из предположения о её унимодальном и симметричном характере. Прямой градиентный анализ HOF-анализ позволяет исследовать вопрос о форме ответа численности вида в градиенте того или иного фактора среды и определить количественные свойства соответствующей проекции экологической ниши.

Полученные результаты свидетельствуют о том, что на основании AIC-критерия наиболее оптимальной моделью, которая описывает ответ численности лебедя-шипуна на изменчивость высоты рельефа, является модель V - унимодальная ассиметричная модель (табл. 3). Анализ кривой ответа показывает, что в диапазоне малых высот вид оказывается достаточно индифферентным к данному геоморфологическому показателю, а при превышении высоты рельефа более 20 м вероятность обнаружения лебедя-шипуна на зимовке существенно снижается. Оптимальной является высота рельефа 18,3 м, а центральная граница экологической ниши составляет $1,45-22,15 \mathrm{M}$.

Таблица 3. Результаты прямого градиентного HOF-анализа ответа численности лебедя-шипуна на градиенты, характеризуемые геоморфологическими параметрами

\begin{tabular}{|c|c|c|c|c|c|c|c|c|}
\hline \multirow[t]{2}{*}{ ЭГП } & \multirow[t]{2}{*}{ Модель } & \multirow[t]{2}{*}{ Минимум* } & \multicolumn{2}{|c|}{ Оптимум } & \multicolumn{2}{|c|}{$\begin{array}{l}\text { Центральная } \\
\text { граница** } 1\end{array}$} & \multicolumn{2}{|c|}{$\begin{array}{c}\text { Центральная } \\
\text { граница } 2\end{array}$} \\
\hline & & & 1 & 2 & минимум & максимум & минимум & максимум \\
\hline dem & V & 0,25 & 18,03 & - & 1,45 & 22,15 & - & - \\
\hline twi & II & 0,10 & 5,00 & - & 5,00 & 10,59 & - & - \\
\hline tpi & VI & 0,28 & $-3,81$ & 4,59 & $-3,81$ & $-0,90$ & 1,96 & 4,59 \\
\hline $\mathrm{mbi}$ & $\mathrm{VI}$ & 0,25 & $-0,71$ & 1,08 & $-0,71$ & $-0,26$ & 0,43 & 1,68 \\
\hline Is & II & 0,25 & 0,29 & - & 0,14 & 0,29 & - & - \\
\hline dir & II & 0,10 & 17,62 & - & 9,92 & 17,62 & - & - \\
\hline diff & VI & 0,24 & 6,43 & 6,49 & 6,41 & 6,45 & 6,47 & 6,51 \\
\hline vert & V & 0,25 & 1,34 & - & 1,34 & 1,35 & - & - \\
\hline vrm & II & 0,28 & 18,82 & - & 4,61 & 18,82 & - & - \\
\hline sh_land & II & 0,07 & 2,20 & - & 1,48 & 2,20 & - & - \\
\hline
\end{tabular}

* - положение минимума, для моделей VI и VII - положение наименьшего ответа между двумя оптимумами; ** центральная граница по Хигарду (Heegard, 2002) рассчитывается как значение градиента, где ответ достигает "exp(-1/2)" от максимального

Ответ численности лебедя-шипуна на вариабельность топографического индекса влажности описывается моделью II - монотонная сигмоида с максимумом в области минимальных значений TWI (рис. 1). Оптимальными являются условия с наименьшими значениями TWI. Таким образом, с одной стороны, лебедь-шипун предпочитает пониженные участки рельефа, а с другой стороны, эти участки должны быть наиболее дренированными.

Отношение численности лебедя-шипуна к индексу топографического положения описывается моделью типа $\mathrm{VI}$ - биомодальная модель с двумя равнозначными оптимумами. Зоной избегания являются участки рельефа с нулевыми значениями TPI, т.е. с выровненным рельефом - равнинная поверхность либо средние части склонов. Оптимальными являются либо участки пониженные вогнутые (TPI в диапазоне от $-3,81$ до -0,90), либо повышенные выгнутые (в диапазоне 1,96-4,59).

Для градиента индекса баланса геомассы также может быть применена модель типа типа VI. Оптимальными для лебедей-шипунов являются местообитания, которые характеризуются диапазоном индекса MBI от -0,71 до 0,26 (участки с накоплением геомассы) и от 0,43 до 1,68 (высокий риск эрозионных процессов). Данный результат подтверждает тяготение лебедя-шипуна к местообитаниям с высоким рельефным разнообразием. 

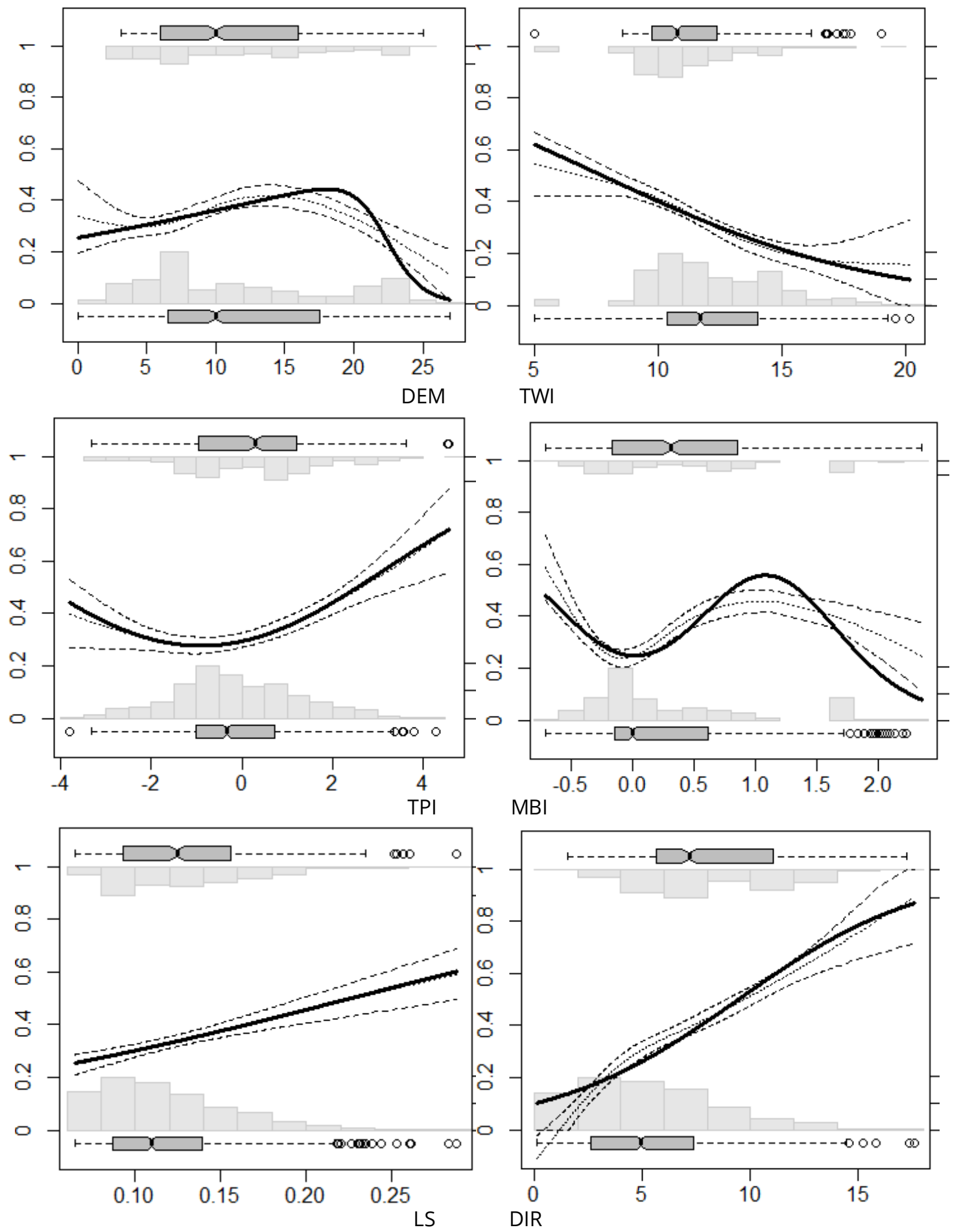

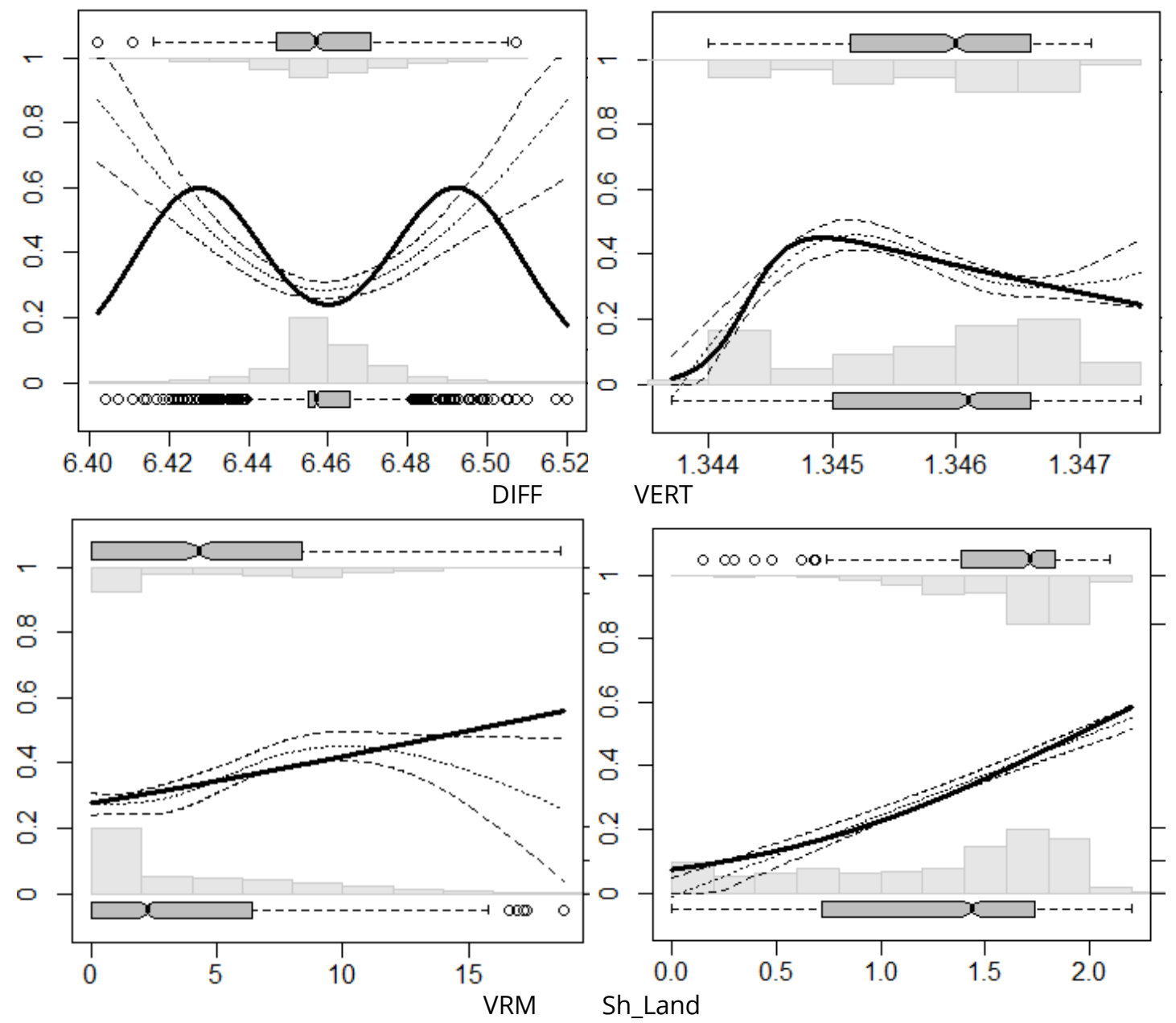

Рис. 14. Иерархические логистические регрессионные модели зависимости численности лебедей-шипунов на зимовке от геоморфологических предикторов

Поведение численности лебедя-шипуна как в градиенте фактора эрозии, так и показателя прямой инсоляции, может быть описано моделью типа II. Лебеди предпочитают участки с наибольшим риском эрозии и наибольшей степенью прямой солнечной инсоляции. В свою очередь, для диффузной инсоляции адекватной является модель VI с двумя зонами оптимума: 6,41-6,45 и 6,47-6,51.

Численность лебедя-шипуна в градиенте высоты над русловой сетью может быть описана моделью типа V. Оптимальными являются показатели 1,34 м в диапазоне 1,34-1,35 м.

Численность лебедя-шипуна в градиенте векторной меры пересеченности местности и индекса геоморфологического разнообразия Шеннона может быть описана моделью типа ІІ. Эти два показателя близки по своей информационной ценности и отражают степень пересеченности местности как сочетание в смежных участках пространства различных форм рельефа. Лебедь-шипун предпочитает местообитания с высокой степенью геоморфологического разнообразия местности.

\section{Обсуждение}

Мозаичность пространственного распределения участков, благоприятных для жизни, играет ключевую роль в контроле численности популяций птиц, включая водоплавающих путем влияния как на демографические параметры популяций, так и на структуру сообществ птиц (Мацюра, 2011; Brown, Dinsmore, 1986; Kurki et al., 2000; Boulinier et al., 2001; Paracuellos, Telleria, 2004; Wilson et al., 2009).

Распределение лебедя-шипуна в прудах в мозаичном ландшафте подвержено влиянию особенностей водоемов (прежде всего, их площади), экологическим особенностям окружения прудов (число прудов в пределах некоторого диапазона дистанций и относительная изоляция), индивидуальных потребностей птиц (этап размножения или промежуток между размножением), а также трофические ресурсы водоемов. Соотношение факторов изменяется на протяжении сезона (Gayet et al., 2011). В зимний период трофические ресурсы водоема играют существенную роль в стациальном распределении лебедей-шипунов (Gayet et al., 2011).

Анализ полученных результатов свидетельствует о том, что данные по численности скоплений лебедя-шипуна подчиняются лог-нормальному распределению. Уже этот результат свидетельствует о том, что изучаемая территория не является однородной средой обитания для указанного вида. Нормальный закон распределения случайной величины возникает тогда, когда на него не действует существенный фактор, либо число действующих 
факторов велико, среди которых нельзя определить ведущий (Puzachenok, 2004). Отклонение от нормального закона численности животных может рассматриваться как результат воздействия лимитирующих факторов. В своей работе мы рассмотрели гипотезу о том, что рельеф может быть синтетическим отражением экологической обстановки, которая определяет пространственное размещение лебедя-шипуна на зимовке.

Современные технологии позволяют описать рельеф местности с помощью цифровой модели рельефа. В свободном доступе существует возможность получить различные модели, которые являются результатом дистанционного зондирования Земли. Эти модели наиболее адекватны для открытых безлесных пространств, в которых нет влияния лесной растительности, приводящей к артефактам в оценке высоты рельефа (Khoroshev, 2016). Ландшафты Присивашья являются удобным объектом для применения информации на основе таких источников данных.

Рельеф является сложным образованием, которое перераспределяет потоки тепла и влаги, а также является результатом сложной истории формирования, обусловленной геологическим строением территории. Все эти обстоятельства делают невозможным с помощью одной переменной описать рельеф как экологический фактор. Высота рельефа может быть преобразована в производные информационные слои, которые могут иметь определенную смысловую нагрузку. Так, топографический индекс влажности отражает роль рельефа в перераспределении влаги (Moore et al., 1993), а высота над русловой сетью является надежным маркером уровня грунтовых вод и может быть использован для картографии почв (Bock, Köthe, 2008). Последнее обстоятельство является весьма важным, так как для ландшафтов Присивашья характерна гидроморфная поясность, связанная с изменением уровня за соленных грунтовых вод в пространстве и во времени (Leontyev, Leontyev, 1956; Pozachenyuk, 1986; Mikhaylov, 2006). Совокупность экогеографических переменных, полученных на основе цифровой модели рельефа, может рассматриваться как комплекс предикторов экологической ниши ебедяшипуна на зимовке.

Как показал пермутационный тест, оси маргинальности и специализации 1-4 статистически достоверно отличаются от случайной альтернативы. Это свидетельствует о том, что выбранные в качестве предполагаемых предикторов экогеографические переменные в действительности способны определять некоторые особенности экологической ниши лебедя-шипуна на зимовке. Этот результат находится в соответствии с данными, полученными при описании экологической ниши зяблика (Zhukov et al., 2015; Zimaroeva et al., 2015) и большой синицы (Zimaroeva et al., 2016). Однако следует отметить, что в указанных работах наряду с геоморфологическими показателями для описания экологической ниши применялись также вегетационные индексы.

Вслед за полимасштабной организацией географического ландшафта (Khoroshev, 2016) мы рассматриваем экологическую нишу животных как иерархически организованное образование. Это значит, что на различных масштабных уровнях свойства экологической ниши могут проявлять себя по-разному (Zhukov et al., 2015). Mы изучили свойства экологической ниши на разных масштабных уровнях и установили, что характер восприятия геоморфологической реальности лебедем-шипуном существенно различен в зависимости от размеров окна пропускания.

Существует определенный диапазон дистанций, в пределах которых геоморфологические предикторы не способны статистически достоверно отразить особенности расположения животных в пространстве. Свойства маргинальности начинают проявляться уже при дистанциях около километра, а специализации - с дистанций более 6 км. На разных диапазонах окна пропускания некоторые предикторы могут проявлять себя по-разному, проявляя инверсию: изменчивость с точностью до наоборот своего значения для определения экологической ниши. Так, по высоте рельефа лебедь-шипун в условиях ландшафта в целом предпочитает пониженные стации, приближенные к водной поверхности. Однако в непосредственной близости к воде лебеди предпочитают дренированные возвышения рельефа.

Факторный анализ экологической ниши (ENFA) отражает важную особенность измерений, которые экологическую ниш определяют. Это, прежде всего, их синтетический характер. Измеряемые манифестные переменные-предикторы одновременно могут характеризовать как ось маргинальности, так и оси специализации. Однако, модель ENFA упрощает форму отображения экологической ниши. В рамках указанного подхода ниша может быть только унимодальной и симметричной. Эта генерализация вполне приемлема для отображения фундаментальной ниши, которая по своей природе сама является абстракцией. Реализованная ниша как результат взаимодействия биотических и абиотических факторов может иметь весьма сложную конфигурацию.

В этой связи прямой градиентный анализ может успешно выполнить описание проекции экологической ниши на отдельные оси экологического пространства. Выполненный анализ в рамках НОF-концепции позволил установить, что варьирование численности лебедя-шипуна на зимовке в градиенте геоморфологических переменных не описывается моделью типа I, т.е. численность находится в зависимости от геоморфологической обстановки. Также важным результатом является то, что градиенты для многих предикторов являются несимметричными и (или) бимодальными. 


\section{Выводы}

Численность скоплений лебедя-шипуна на зимовке в Присивашье подчиняется лог-нормальному распределению. Среднее арифметическое значение численности скоплений составляет 532,1 2203,1 экз., медиана - 129 экз. с диапазоном варьирования от 5 до 8000 экз. Отклонение от нормального закона численности животных может рассматриваться как результат воздействия лимитирующих факторов. В работе полученны подтверждения гипотезы о том, что рельеф является синтетическим отражением экологической обстановки, которая определяет пространственное размещение лебедя-шипуна на зимовке.

Для количественной характеристики рельефа большое значение имеет цифровая модель рельефа и производные информационные слои, которые раскрывают различные аспекты функционального значения поверхности земли как фактора, организующего структуру живого покрова. Оси маргинальности и специализации 1-4, полученные в результате ENFA-процедуры, статистически достоверно отличаются от случайной альтернативы. Это свидетельствует о том, что выбранные в качестве предполагаемых предикторов экогеографические переменные, в действительности способны определять некоторые особенности экологической ниши лебедя-шипуна на зимовке.

Наибольшей маргинальностью характеризуются категориальные переменные, которые указывают на различные формы рельефа. Наибольшим предпочтением отличаются открытые склоны. Континуальные переменные дополняют особенности этих стаций. Открытые склоны, закономерно, характеризуются большим фактором эрозии, находятся в более пересеченной местности и в условиях большего геоморфологического разнообразия местности. Континуальные переменные характеризуются большим значением в определении специализации экологической ниши лебедя-шипуна.

Полимасштабная организация географического ландшафта является причиной иерархической организации экологической ниши. На различных масштабных уровнях свойства экологической ниши проявляют себя поразному. Свойства экологической ниши на разных масштабных уровнях указывают на то, что характер восприятия геоморфологической реальности лебедем-шипуном существенно различен в зависимости от размеров окна пропускания, определяющего масштабный уровень рассмотрения экологической ниши.

Существует определенный диапазон дистанций, в пределах которых геоморфологические предикторы не способны статистически достоверно отразить особенности расположения животных в пространстве. Свойства маргинальности начинают проявляться уже при дистанциях около километра, а специализации - с дистанций более 6 км. На разных диапазонах окна пропускания некоторые предикторы могут проявлять инверсию: изменчивость с точностью до наоборот своего значения для определения экологической ниши.

Прямой градиентный анализ позволил оценить проекции экологической ниши на отдельные оси экологического пространства. Анализ в рамках HOF-концепции показал, что варьирование численности лебедяшипуна на зимовке в градиенте геоморфологических переменных не описывается моделью типа I, т.е. численность находится в зависимости от геоморфологической обстановки. Также важным результатом является то, что градиенты для многих предикторов являются несимметричными и (или) бимодальными.

\section{References}

Andryushchenko, A.Yu., Zhukov, A.V. (2016). Masshtabno-zavisimye jeffekty v strukture jekologicheskoj nishi lebedjashipuna Cygnus olor (Gmelin, 1803) v period zimovki v predelah zaliva Sivash. Biological Bulletin of Bogdan Chmelnitskiy Meitopol State Pedagogical University, 6(3), 234-247 (in Russian)

Andryushchenko, Yu., Katysh, S., Popenko, V., Siokhin, V., Chercnichko, J. (2010). Metodiki obliku ptahiv dlja ocinki stanu resursiv mislivs'kih vidiv vodno-bolotnih ptahiv u mislivs'kih gospodarstvah Azovo-Chornomors'kogo regionu Ukraïni. Melitopol, Laguna (in Ukrainian).

Andryushchenko, Yu.A. (2009). Unifikacija metodik srednezimnih uchetov v Azovo-Chernomorskom regione Ukrainy. Bjulleten' ROM: Itogi srednezimnego ucheta vodno-bolotnyh ptic 2006 goda v Azovo-Chernomorskom regione Ukrainy: adaptacija metodik IWC i ih aprobacija, 4, 4-12. (in Russian)

Bock, M., Köthe, R.,(2008). Predicting the Depth of hydrologic Soil Characteristics. Hamburger Beiträge zur Physischen Geographie und Landschaftsökologie, Heft 19, 13-22.

Boehner, J., Antonic, O. (2009). Land Surface Parameters Specific to Topo-Climatology (pp. 195-226). Hengl, T. \& Reuter, H.I. (Eds.). Geomorphometry. Concepts, Software, Applications. Elsevier.

Calenge, C., Basille, M. (2008). A general framework for the statistical exploration of the ecological niche. Journal of Theoretical Biology, 252, 674-685.

Caruso, N., Guerisoli, M., Luengos Vidal, E.M., Castillo, D., Casanave, E.B., Lucherini, M. (2015). Modelling the ecological niche of an endangered population of Puma concolor: First application of the GNESFA method to an elusive carnivore. Ecological Modelling, 297, 11-19.

Davidov, O.V., Rozkos, N.O., Rozkos, O.M. (2013). Zagal'ni osoblivosti poshirennja roslinnosti na berezi zatoki Sivash, Azovs'ke more. Visnik Odes'kogo nacional'nogo universitetu. Geografichni ta geologichni nauki, 18(3), 57-65 (in Ukrainian). 
De Angelo, C., Paviolo, A., Di Bitetti, M. (2011). Differential impact of landscape transformation on pumas (Puma concolor) and jaguars (Panthera onca). The Upper Paraná Atlantic Forest. Divers. Distrib, 17, 422-436.

Dehn, M., Gärtner, H., Dikau, R. (2001). Principles of semantic modeling of landform structures. Computers and Geoscience. Computers \& Geosciences, 27, 1005-1010.

Galparsoro, I., Borja, Á., Bald, J., Liria, P., Chust, G. (2009). Predicting suitable habitat for the European lobster (Homarus gammarus) on the Basque continental shelf (Bay of Biscay), using Ecological-Niche Factor Analysis. Ecol. Model, 220, 556-567.

Guisan, A., Weiss, S.B., Weiss, A.D. (1999). GLM versus CCA spatial modeling of plant species distribution. Plant Ecology, 143, 107-122.

Hall, L., Krausman, P., Morrison, M. (1997). The habitat concept and a plea for standard terminology. Wildlife Society Bulletin, 25, 173-182.

Halstead, B.J., Wylie, G.D., Casazza, M.L. (2010). Habitat suitability and conservation of the giant gartersnake (Thamnophis gigas) in the Sacramento Valley of California. Copeia, 4, 591-599.

Hemery, L., Galton-Fenzi, B., Améziane, N., Riddle, M., Rintoul, S., Beaman, R., Post, A., Eléaume, M. (2011). Predicting habitat preferences for Anthometrina adriani (Echinodermata) on the East Antarctic continental shelf. Mar. Ecol. Prog. Ser, 441, 105-116.

Hirzel, A.H., Hausser, J., Chessel, D., Perrin, N. (2002). Ecological-niche factor analysis: How to compute habitatsuitability maps without absence data? Ecology, 83, 2027-2036.

Huisman, J., Olff, H., Fresco, L.F.M. (1993). A hierarchical set of models for species response analysis. Journal of Vegetation Science, 4, 37-46.

Inventarizacija i kadastrovaja harakteristika vodno-bolotnyh ugodij juga Ukrainy. (1993). I.I.Chernichko (Ed.). Bull. № 1. Melitopol, Branta (in Russian)

Jansen, F., Oksanen, J. (2013). How to model species responses along ecological gradients - Huisman-Olff-Fresco models revisited. Journal of Vegetation Science, 24, 1108-1117.

Kolomijchuk, V.P., Matsyura, A.V. (1998). Biologicheskoe raznoobrazie i sistema vzaimootnoshenij rastitel'nosti i kolonial'no gnezdjashhihsja ptic ostrovnyh sistem. Proceed. Int. Conf. "Voprosy bioindikacii i jekologii”. Zaporozh'e, Pavel (in Russian)

Kondrat'ev, A.V. (2002). Ekologija pitanija gusej v Arktike i na puti k nej. Kazarka: Bjulleten' rabochej gruppy po guseobraznym Severnoj Evrazii, 8, 79-99 (in Russian)

Landshafty i fiziko-geograficheskoe rajonirovanie. (1985). In Priroda USSR. Kiev. Naukova dumka (in Russian)

Leontyev, V.K., Leontyev, O.K. (1956). Osnovnye cherty geomorfologii Sivashskoj laguny. Vestnik Moskovskogo universiteta. Ser. Geografija, 2, 185-194 (in Russian)

Liseckij, F.N., Polovinko V.V. (2012). Eerozionnye kateny na zemljanyh fortifikacionnyh sooruzhenijah. Geomorfologija, 2, 65-78 (in Russian)

Lysenko, V.I. (1991). Fauna Ukrainy. Tom 5. Pticy. Vyp. 3. Guseobraznye. Kiev, Naukova dumka (in Russian)

Marushevskky, G.B., Kostyushin, V.A., Siokhin, V.D. (2005). Sivash: priroda i ljudi. Kiev, Wetlands International. (in Russian)

Matsyura, A.V. (1999). Znachenie Sivasha dlja podderzhanija bioraznoobrazija kolonial'no gnezdjashhihsja okolovodnyh ptic vodno-bolotnyh ugodij juga Levoberezhnoj Ukrainy. Zapovidna sprava v Ukraïni, 5(2), 37-39. (in Russian)

Matsyura, A.V. (2011). Landshaftno-biotopicheskoe znachenie ostrovov Sivasha dlja gnezdjashhihsja ptic. Biological Bulletin of Bogdan Chmelnitskiy Melitopol State Pedagogical University, 1, 53-58. (in Russian)

McCool, D.K., Renard, K.G., Foster, G.R., (1994). The Revised Universal Soil Loss Equation. Proceed. Int. Workshop on Soil Erosion. The Center for Technology Transfer and Pollution Prevention, Purdue University. West Lafayette, IN., USA.

Mikhaylov, V.A. (2006). Geograficheskaja eevoljucija Sivashskoj laguny. Kul'tura narodov Prichernomor'ja, 6(82), 11-14 (in Russian)

Mitchel, Dzh.K., Bubenzer, G.D. (1984). Raschety poter' pochvy. Erozija pochv. Moscow, Kolos (in Russian)

Moeller, M., Volk, M., Friedrich, K., Lymburner, L. (2008). Placing soil-genesis and transport processes into a landscape context: A multiscale terrain-analysis approach. Journal of Plant Nutrition and Soil Science, 171, 419-430.

Moore, I.D., Nortin, T.W., Williams, J.E. (1993). Modelling environmental heterogeneity in forested landscapes. Journal of Hydrology, 150, 717-747.

Olaya, V., Conrad, O. (2008). Geomorphometry in SAGA. In Hengl, T. \& Reuter, H.I. (Eds.). Geomorphometry: concepts, software, applications. Elsevier.

Panagos, P.A., Borrelli, P. Meusburger, K. (2015). New European Slope Length and Steepness Factor (LS-Factor) for Modeling Soil Erosion by Water. Geosciences, 5, 117-126.

Pozachenyuk, E.A. (1986). K metodike fiziko-geograficheskogo rajonirovanija po vnutriregional'nym zakonomernostjam(na primere Kryma). Prirodnoe rajonirovanie i problema ohrany prirody. Ufa, Bashkir University Press (in Russian)

Priroda Ukrainskoj SSR. Morja i vnutrennie vody. (1987). Greze, V.N., Polikarpov, G.G., Romanenko, V.D. (Eds.). Kiev, Naukova dumka (in Russian) 
Sabinevskiy, B.V. (1977). Azovo-Chernomorskoe poberezh'e Ukrainy - kompleksnyj rezervat vodno-bolotnyh ptic. Vestnik zoologii, 2, 44-54 (in Russian)

Sappington, J.M., Longshore, K.M., Thompson, D.B. (2007). Quantifying landscape ruggedness for animal habitat analysis: a case study using desert bighorn sheep in the Mojave Desert. Journal of Wildlife Management, 71(5), 1419-1426.

Siokhin, V.D., Aleksandrov, B.G., Chernichko, J.I. (2014). Ocinka landshaftnogo ta biologichnogo riznomanittja integral'nimi biologichnimi indikatorami ta markerami. Melitopol. Melitopol State Pedagogical University (in Russian)

Thiebot, J.-B., Lescroel, A., Pinaud, D., Trathan, P.N., Bost, C.-A., (2011). Larger foraging range but similar habitat selection in non-breeding versus breeding subAntarctic penguins. Antarctic Science, 23, 117-126.

Valle, M., Boria, Á., Chust, G., Galparsoro, I., Garmendia, J.M. (2011). Modelling suitable estuarine habitats for Zostera noltii, using Ecological Niche Factor Analysis and Bathymetric LiDAR. Estuar. Coast. Shelf Sci, 94, 144-154.

Wischmeier, W.H., Smith, D.D. (1978). Predicting rainfall erosion losses. Agricultural handbook. Washington. No. 537.

\section{Citation:}

Zhukov, A.V., Andryushchenko, A.Yu. (2017). Relief and ecological niche of mute swan (Cygnus olor (Gmelin, 1803)) wintering in Sivash. Acta Biologica Sibirica, 3 (2), 20-45.

Submitted: 28.03.2016. Accepted: 10.06.2017

cross ref $\underline{\text { http://dx.doi.org/10.14258/abs.v3i2.2730 }}$

(C) 2017 by the authors. Submitted for possible open access publication under the terms and conditions of the Creative Commons Attribution (CC BY) license (http://creativecommons.org/licenses/by/4.0/). 